Article

\title{
Integration Design and Optimization Control of a Dynamic Vibration Absorber for Electric Wheels with In-Wheel Motor
}

\author{
Mingchun Liu ${ }^{1, *}$ (D), Feihong Gu ${ }^{2}$, Juhua Huang ${ }^{1}$, Changjiang Wang ${ }^{3}$ and Ming Cao ${ }^{1}$ \\ 1 School of Mechatronics Engineering, Nanchang University, Nanchang 330031, China; \\ huangjuhua6@163.com (J.H.); caoming@ncu.edu.cn (M.C.) \\ 2 School of Automotive Engineering, Jilin University, Changchun 130022, China; gufh17@mails.jlu.edu.cn \\ 3 Jiangxi Kingchun Electric Control Technology Co., Ltd., Shangrao 334199, China; wangcj@kcectech.com \\ * Correspondence: liumingchun@ncu.edu.cn; Tel.: +86-(0791)-8396-9635
}

Received: 19 November 2017; Accepted: 30 November 2017; Published: 5 December 2017

\begin{abstract}
This paper presents an integration design scheme and an optimization control strategy for electric wheels to suppress the in-wheel vibration and improve vehicle ride comfort. The in-wheel motor is considered as a dynamic vibration absorber (DVA), which is isolated from the unsprung mass by using a spring and a damper. The proposed DVA system is applicable for both the inner-rotor motor and outer-rotor motor. Parameters of the DVA system are optimized for the typical conditions, by using the particle swarm optimization (PSO) algorithm, to achieve an acceptable vibration performance. Further, the DVA actuator force is controlled by using the alterable-domain-based fuzzy control method, to adaptively suppress the wheel vibration and reduce the wallop acting on the in-wheel motor (IWM) as well. In addition, a suspension actuator force is also controlled, by using the linear quadratic regulator (LQR) method, to enhance the suspension performance and meanwhile improve vehicle ride comfort. Simulation results demonstrate that the proposed DVA system effectively suppresses the wheel vibration and simultaneously reduces the wallop acting on the IWM. Also, the alterable-domain-based fuzzy control method performs better than the conventional ones, and the LQR-based suspension exhibits excellent performance in vehicle ride comfort.
\end{abstract}

Keywords: electric wheel; in-wheel motor; dynamic vibration absorber; integration design; alterable-domain-based fuzzy control; particle swarm optimization; linear quadratic regulator

\section{Introduction}

In recent years, electric vehicles (EVs) have entered a new paradigm due to their advantages, compared to vehicles with internal combustion engines (ICEs), in terms of energy efficiency and environmental friendliness [1-4]. Central motor solutions, which are similar to ICE vehicles and currently dominate the EVs market, are still rather complex due to the number of moving parts. As a result, vehicle developers have been proactively seeking appropriate powertrain solutions for their high-quality EV products [5,6]. By virtue of the development of in-wheel motors (IWMs), the IWM propulsion system has been considered a promising solution to comprehensively improve EVs' performance. In an in-wheel-motor electric vehicle (IWMEV), the motor, brake, reducer and hub are mounted into the wheel. The highly integrated electric wheel provides great benefits to the vehicle space layout [7], vehicle dynamics control [8], energy conservation [9], and redundant propulsion [10]. Nevertheless, these merits are accompanied with technical challenges. The highly integrated components challenge the design of electric wheels. What is more, the IWMs significantly increase the vehicle unsprung mass. Research shows that removing the propulsion system from the 
vehicle body to the wheels can increase each wheels' mass by $30 \mathrm{~kg}$ or more [11]. This large unsprung mass shall result in worsened wheel vibration and vehicle vertical performance [12], such as reduction of vehicle ride comfort [13], deterioration of road friendliness [14], reduction of motor reliability under the large wallop [15], and invalidation of suspension control methods [16].

In conventional vehicle dynamics research, active and semi-active suspensions are adopted to improve vehicle ride comfort and road-holding performance [17-22]. Research for IWMEVs has been conducted based on that notion. Jin [23] proposed a magneto-rheological semi-active suspension for an IWMEV, whereby an adjustable damping force was controlled to improve vehicle ride comfort. Jing and Wang [24] designed an $H_{\infty}$ robust fault-tolerant active suspension controller for an IWMEV to decrease the motor vibration and reduce the dynamic load applied to the motor bearing. Shao [25] investigated a fault-tolerant fuzzy $H_{\infty}$ control approach for the active suspension for an IWMEV in the presence of sprung mass variation, actuator faults, and control input constraints. The robust $H_{\infty}$ control can deal with system complexities such as the model uncertainty, time delay, and time constant uncertainty $[26,27]$, and can effectively decrease the sprung mass vertical acceleration (SVA), suspension dynamic deflection (SDD), and tire dynamic load (TDL) in active and semi-active suspensions [28,29]. Another electric wheel drawback is that the vertical wallop acting on the wheel directly impacts the motor. Furthermore, motor bearings easily wear and fail due to the fast change of road conditions and large wallop, resulting in magnet gap deformation, unbalanced magnetic force oscillations [30] and torque ripple [31]. Therefore, besides reducing vehicle SVA, SDD and TDL, it is necessary to address the vibration suppression in the electric wheel to reduce the motor vertical wallop (MVW).

Intensive research activities have contributed to several solutions for electric wheel vibration optimization, such as the lightweight design of motors and in-wheel vibration suppression. Axial flux motors, featured with high power density and high efficiency, have a large diameter to length ratio, and meet most of electrical requirements and physical limits for EVs application. Thus, axial flux motors are effective to reduce electric wheel mass and vibration [32]. Takahashi [33] designed a ferrite permanent magnet based on a low cost in-wheel axial gap motor, in which an open slot structure was utilized instead of a semi-closed slot structure to reduce motor size and weight. Nikam et al. [34] investigated a permanent magnet brushless motor with a segmented rotor for IWMEVs, in which the end-winding effects and motor weight were reduced by using a concentrated winding method. Luo [35] proposed a hybrid lightweight method to optimize the motor size and topology structure. Besides the light weight of IWMs, the in-wheel vibration suppression is an effective strategy to reduce electric wheel vibration as well. Luo and Tan [36] presented an topological structure with a built-in mount system for the electric wheel, in which the IWM was isolated elastically from the unsprung mass by using rubber bushings to transfer the motor to the sprung mass. Based on that, Tan [37] further optimized the parameters of the suspension and rubber bushings, and demonstrated that the magnet gap deformation achieved a great improvement. Whereas, the built-in rubber bushings essentially behave just like passive vibration absorbers, whose effectiveness shall be weakened on the complicated and varied pavement. Bridgestone [38] developed an electric wheel with a dynamic vibration absorber (DVA), whereby the motor was designed as an absorber to reduce the wheel vibration. Chen [39] investigated several methods to diminish the negative effects of the large unsprung mass on wheel-side-drive EVs, including the suspension and reducer integrated method, the DVA method, and the active and energy regenerative suspension method. Wang [40] achieved an optimization finite-frequency $H_{\infty}$ control of active suspension with a dynamic vibration absorber (DVA) for an IWMEV to improve vehicle ride comfort, in which the DVA was introduced as an additional component of electric wheel and, to a certain extent, shall further increase the unsprung mass. Ma [41] proposed an active vibration control of the electric wheel by adding a linear motor between the IWM stator and wheel shaft. The controllable DVA system is beneficial to reduce electric wheel vibration, whereas, it is difficult to mount the DVA into wheel because of the size limitation. In addition, 
the in-wheel DVA system couples with the suspension system, but fewer studies can be found on the coordinated control of the in-wheel DVA system and suspension system.

This study addresses the drawbacks mentioned above, such as the integration design of electric wheel, and the coordinated vibration control of the in-wheel DAV and suspension. The main contributions of this study lie in the following aspects. First, in order to minimize the in-wheel motor (IWM) vibration, the IWM is considered as a dynamic vibration absorber (DVA), which is isolated from the unsprung mass by using an in-wheel vibration suppression system. The DVA system is applicable for both the inner-rotor IWMs and outer-rotor IWMs. Second, The DVA parameters are optimized by using the particle swarm optimization (PSO) algorithm, such that the DVA can passively suppress the motor vibration. In addition, the actuators of the DVA and vehicle suspension are coordinately controlled, in which the DVA actuator force is controlled by using the alterable-domain-based fuzzy method to further reduce the motor vertical wallop, and meanwhile the suspension actuator force is controlled by using the linear quadratic regulator (LQR) method to improve vehicle ride comfort. Finally, the effectiveness of the proposed methods is validated through simulations under various conditions.

The rest of this paper is organized as follows: the integrated design of the DVA-based electric wheels is introduced in Section 2. A quarter-vehicle dynamics model with the DVA-based electric wheel is established in Section 3. The proposed controllers of the DVA system and suspension system are presented in Section 4. Section 5 demonstrates the simulation results, followed by a summary of the conclusions in Section 6.

\section{Integration Designed of the Dynamic-Vibration-Absorber-Based Electric Wheel}

An electric wheel is driven by a high-speed inner-rotor motor or a low-speed outer-rotor motor. Figure 1 shows the conventional configurations of the two kinds of electric wheels. As shown in Figure 1a, the electric wheel with inner-rotor motor is used in combination with a fixed planetary reducer. Since low torque is required at higher vehicle speeds, the inner-rotor has a smaller size, lighter weight and lower costs. Figure $1 \mathrm{~b}$ shows a direct-drive configuration of the electric wheel with outer-rotor motor, in which the motor has a bigger size and weight. Whereas, the absence of the reducer simplifies the configuration, and improves the overall reliability and efficiency.

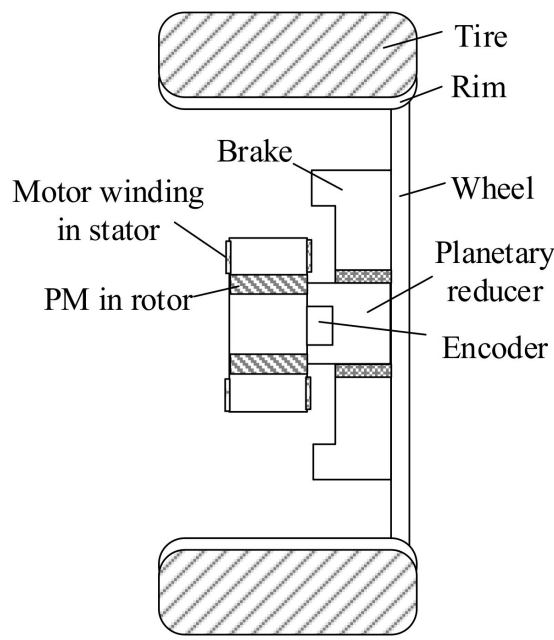

(a)

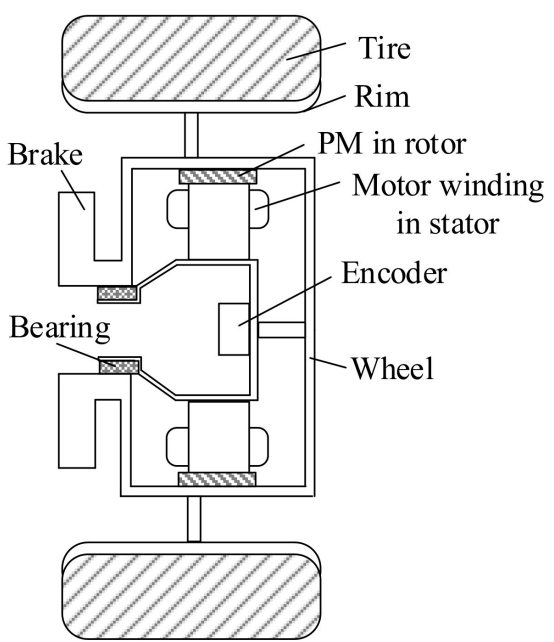

(b)

Figure 1. Electric wheel configurations. (a) Electric wheel with inner-rotor motor; (b) Electric wheel with outer-rotor motor.

In a conventional electric wheel, the motor stator and rotor (or reducer for an inner-rotor motor) are rigidly connected to the wheel shaft and hub, respectively. When road excitation acts on the wheel, 
the motor is directly shocked due to the rigid connections, resulting in deteriorated vibration of the electric wheel.

In this section, the IWM is considered as a dynamic vibration absorber, which is isolated from the wheel shaft and hub by using an in-wheel spring and a damper with a controllable actuator, whereby the above rigid connections are replaced by flexible connections. Figure 2 shows the integration design of the proposed DVA-based electric wheel with outer-rotor motor. As shown in Figure 2a, to realize the flexible connection of the motor stator, a spring is introduced to link the stator extension with sprung mass, and an in-wheel damper is installed into the stator extension and sheathed outside the wheel shaft. The in-wheel damper is featured with a controllable actuator, which can be controlled to actively suppress the wheel vibration. Notably, the wheel shaft penetrates through the hollow-stator as shown in Figure 2b. In addition, to realize the flexible connection of the motor rotor, a translational pair is designed to link the rotor with wheel hub, which ensures a proper vertical relative motion between the rotor and wheel hub. As shown in Figure 3, the translational pair consists of a hub-side disc, a center disc, and a rotor-side disc. The two side discs are rigidly connected to the wheel hub and motor rotor, respectively. And both sides of the center disc are grooved to hold the other two discs in linear position. When the wheel vibration occurs, the linear relative motion between the rotor and wheel hub is guided by the translational pair, while the torque transmission is not affected.

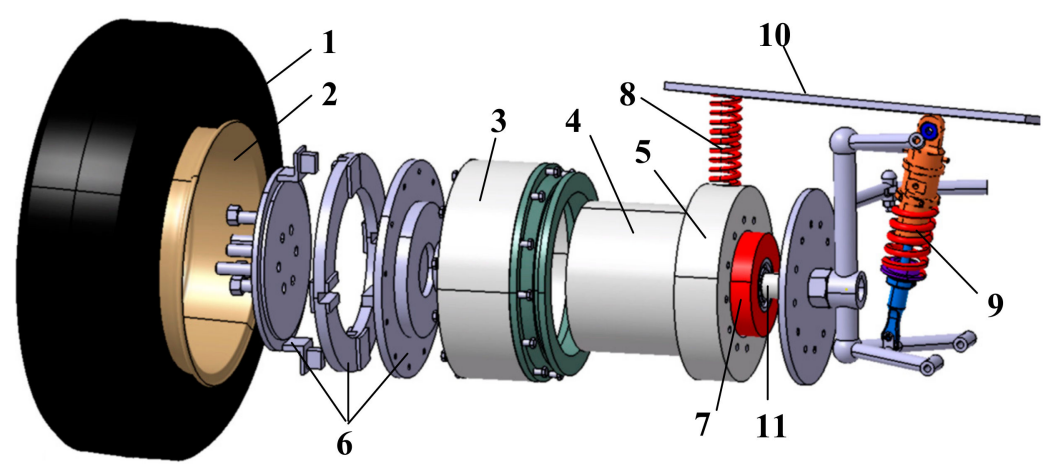

(a)

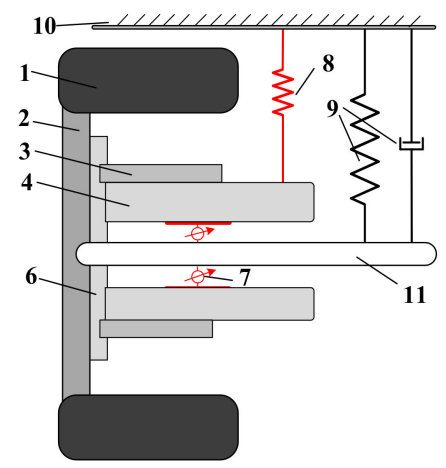

(b)

Figure 2. DVA-based electric wheel with outer-rotor motor. (a) Exploded view; (b) Schematic diagram. 1-Wheel; 2-Hub; 3-Motor rotor; 4-Motor stator; 5-Stator extension; 6-Translational pair; 7-In-wheel damper with a controllable actuator; 8-In-wheel spring; 9-Suspension; 10-Sprung mass; 11-Wheel shaft.

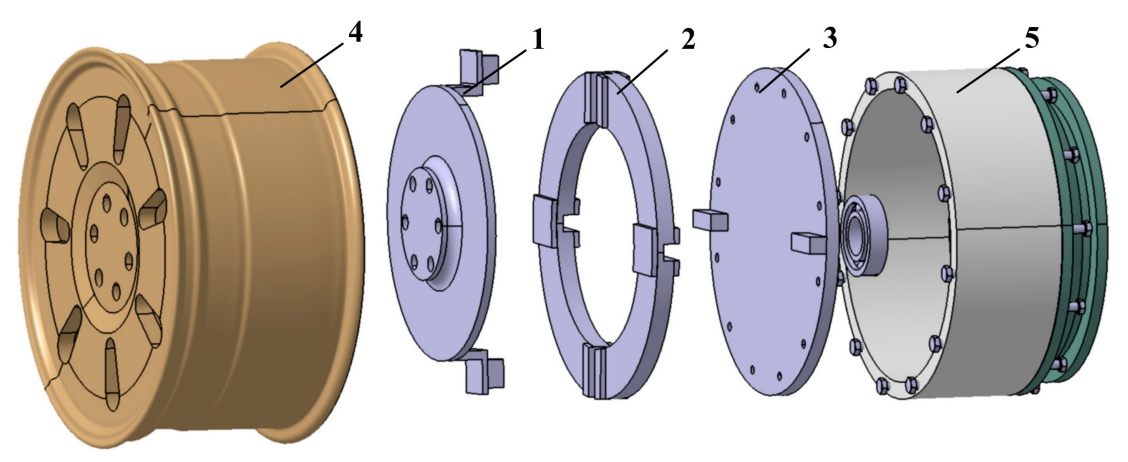

Figure 3. Translational pair between the rotor and wheel hub. 1-Hub-side disc; 2-Center disc; 3-Rotor-side disc; 4-Hub; 5-Motor rotor.

Similarly, the proposed DVA system is also applicable to the inner-rotor motor. As shown in Figure 4, the outer-stator and inner-rotor are flexibly connected to the wheel shaft and hub by using the spring-damper system and translational pair, respectively. The flexible connections in Figure $4 \mathrm{a}$ 
are the same as those in Figure 2a. Notably, the rotor-side disc of translational pair is connected to the inner-rotor through a planetary reducer. As shown in Figure $4 b$, the wheel shaft only penetrates through the hollow-stator extension.

The proposed integrated configurations of the DVA-based electric wheels primarily change the connections between the motor and unsprung mass, rather than the motor structure. Thus, the DVA system is applicable to most of the commonly used in-wheel motors.

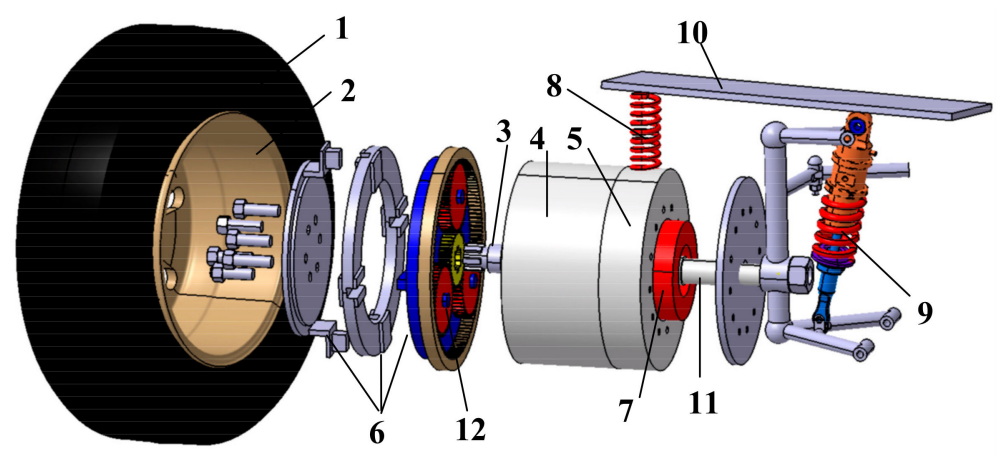

(a)

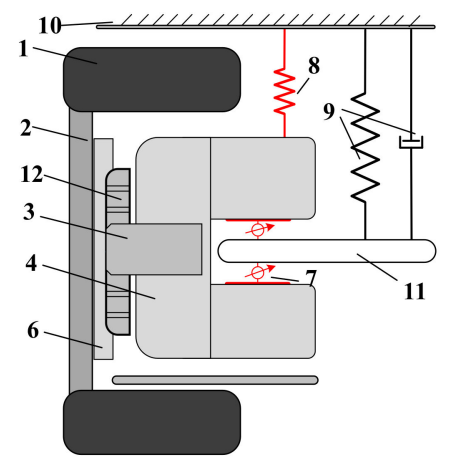

(b)

Figure 4. DVA-based electric wheel with inner-rotor motor. (a) Exploded view; (b) Schematic diagram. 1-Wheel; 2-Hub; 3-Motor rotor; 4-Motor stator; 5-Stator extension; 6-Translational pair; 7-In-wheel damper with a controllable actuator; 8-In-wheel spring; 9-Suspension; 10-Sprung mass; 11-Wheel shaft; 12-Planetary reducer.

\section{Quarter-Vehicle System Modeling and Problem Statement}

\subsection{Quarter-Vehicle System Modeling}

Schematic diagrams of the physical quarter-vehicle models with the conventional electric wheel and the DVA-based electric wheel are shown in Figure 5a,b, respectively. In Figure 5, $m_{s}$ and $m_{w}$ represent the quarter-vehicle sprung mass and wheel mass (including the wheel assembly parts), respectively; $m_{e s}$ and $m_{e r}$ represent the motor stator mass and rotor mass (including rotor, brake disc and reducer), respectively; $K_{s}$ and $C_{S}$ represent the stiffness and damping of vehicle suspension, respectively; and $K_{t}$ stands for the tire vertical stiffness. Moreover, $C_{d}$ and $K_{d}$ represent the stiffness and damping of the proposed DVA, respectively; and $f_{s}$ and $f_{d}$ are the controlled force of the suspension controllable actuator and the DVA controllable actuator, respectively. In addition, $x_{s}, x_{e}$ and $x_{w}$ represent the vertical displacement of the sprung mass, electric motor, and wheel, respectively, and $q(t)$ is the pavement input to the tire. Note that the tire damping is omitted in the models.

As shown in Figure 5a, in the conventional electric wheel, the IWM is rigidly connected to the wheel, and is considered as a part of the unsprung mass. As noted in Section 2, in the proposed DVA-based electric wheel, the rigid connection between the motor stator and the wheel shaft is replaced by a flexible connection. Besides, a translation pair is utilized to guide the relative vertical motion between the wheel hub and motor rotor, whereby the motor has one degree of translational freedom in vertical direction, without vertical force from the wheel hub acting on the rotor in the travel range of translational pair. Therefore, both the out-rotor and inner-rotor electric wheels based on the DVA can be generally modelled as Figure 5 b. 


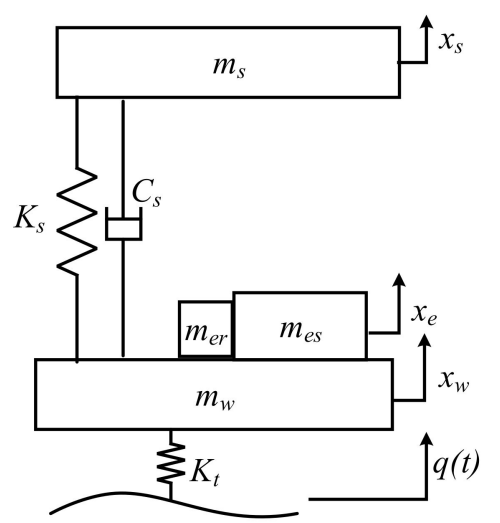

(a)

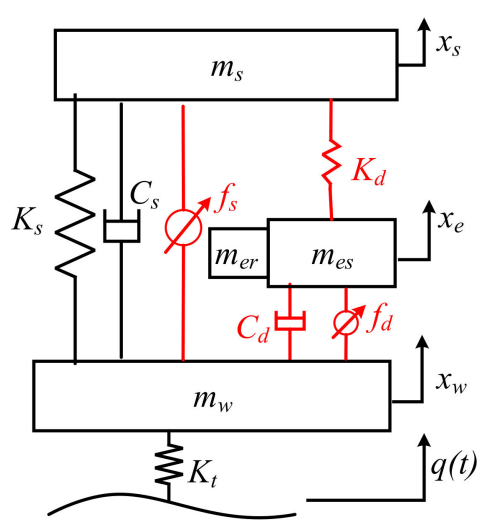

(b)

Figure 5. Quarter-vehicle model with: (a) Conventional electric wheel; and (b) DVA-based electric wheel.

Based on the Newton laws, the motion equations of the quarter-vehicle with the DVA-based electric wheel can be formulated as

$$
\begin{gathered}
m_{w} \ddot{x}_{w}+K_{s}\left(x_{w}-x_{s}\right)+C_{s}\left(\dot{x}_{w}-\dot{x}_{s}\right)+C_{d}\left(\dot{x}_{w}-\dot{x}_{e}\right)+K_{t}\left(x_{w}-q\right)+f_{s}+f_{d}=0 \\
\left(m_{e r}+m_{e s}\right) \ddot{x}_{e}+C_{d}\left(\dot{x}_{e}-\dot{x}_{w}\right)+K_{d}\left(x_{e}-x_{s}\right)-f_{d}=0 \\
m_{s} \ddot{x}_{s}+K_{s}\left(x_{s}-x_{w}\right)+C_{s}\left(\dot{x}_{s}-\dot{x}_{w}\right)+K_{d}\left(x_{s}-x_{e}\right)-f_{s}=0
\end{gathered}
$$

We define the following vehicle state variables:

$$
x=\left[\begin{array}{llllll}
\dot{x}_{w} & \dot{x}_{e} & \dot{x}_{s} & x_{s}-x_{w} & x_{s}-x_{e} & q-x_{w}
\end{array}\right]^{\mathrm{T}}
$$

The Equations (1)-(3) can be expressed by a state space equation as:

$$
\dot{x}=\mathbf{A} x+\mathbf{B} u+\mathbf{G} w
$$

where:

$$
\begin{gathered}
\mathbf{A}=\left[\begin{array}{cccccc}
-\left(C_{s}+C_{d}\right) / m_{w} & C_{d} / m_{w} & C_{s} / m_{w} & K_{s} / m_{w} & 0 & K_{t} / m_{w} \\
C_{d} / m_{e} & -C_{d} / m_{e} & 0 & 0 & K_{d} / m_{e} & 0 \\
C_{s} / m_{s} & 0 & -C_{s} / m_{s} & -K_{s} / m_{s} & -K_{d} / m_{s} & 0 \\
-1 & 0 & 1 & 0 & 0 & 0 \\
0 & -1 & 1 & 0 & 0 & 0 \\
-1 & 0 & 0 & 0 & 0 & 0
\end{array}\right], \\
\mathbf{B}=\left[\begin{array}{cccccc}
-1 / m_{w} & 0 & 1 / m_{s} & 0 & 0 & 0 \\
-1 / m_{w} & 1 / m_{e} & 0 & 0 & 0 & 0
\end{array}\right]^{\mathrm{T}}, \\
\mathbf{G}=\left[\begin{array}{lllll}
0 & 0 & 0 & 0 & 1
\end{array}\right]^{\mathrm{T}}, \\
u=\left[\begin{array}{ll}
f_{s} f_{d}, w \\
{ }^{\mathrm{T}}, w=q(t), m_{e}=m_{e r}+m_{e s} .
\end{array}\right.
\end{gathered}
$$




\subsection{Problem Statement}

In order to investigate the coordination control of vehicle suspension system and in-wheel DVA system, four evaluation indexes, vibration performance, ride comfort, suspension deflection, road holding, and IWM dynamic force vibration, are considered as the optimization objectives.

(1) Ride comfort. Vehicle ride comfort is mainly quantified by using the sprung mass vertical acceleration (SVA). Thus, the first optimization objective which should be minimized is the SVA, which is expressed as:

$$
a_{s}=\ddot{x}_{s}
$$

(2) Suspension deflection. The suspension dynamic deflection (SDD) should be constrained and not exceed its travel limit. That is:

$$
d_{s}=x_{s}-x_{w} \text {, and }\left|d_{s}\right| \leq d_{\max }
$$

(3) Road holding. A firm uninterrupted contact of wheels to the road should be ensured to ensure the road holding and vehicle safety. Therefore, the tire dynamics load (TDL) should be minimized as well. The TDL is defines as:

$$
F_{w}=K_{t}\left(x_{w}-q\right)
$$

(4) IWM dynamic force. The IWM dynamic force can be quantified by using the motor vertical wallop (MVW), which should be suppressed to be as small as possible. The MVW is defined as

$$
F_{e}=m_{e} \ddot{x}_{e}
$$

In order to improve the vibration performance of vehicle suspension system and in-wheel DVA system, the above four evaluation indexes, the SVA, SDD, TDL, and MVW, should be optimized. The four evaluation indexes are defined as the output variables to satisfy the performance optimization. That is:

$$
y=\left[\begin{array}{llll}
a_{s} & d_{s} & F_{w} & F_{e}
\end{array}\right]^{\mathrm{T}}
$$

Thus, the control system, including the quarter-vehicle model and the output variables, can be expressed by the following state space equations:

$$
\left\{\begin{array}{l}
\dot{x}=\mathbf{A} x+\mathbf{B} u+\mathbf{G} w \\
y=\mathbf{C} x+\mathbf{D} u
\end{array}\right.
$$

where:

$$
\begin{gathered}
\mathbf{C}=\left[\begin{array}{cccccc}
C_{s} / m_{s} & 0 & -C_{s} / m_{s} & -K_{s} / m_{s} & -K_{d} / m_{s} & 0 \\
0 & 0 & 0 & 1 & 0 & 0 \\
0 & 0 & 0 & 0 & 0 & -K_{t} \\
C_{d} & -C_{d} & 0 & 0 & K_{d} & 0
\end{array}\right], \\
\mathbf{D}=\left[\begin{array}{cccc}
1 / m_{s} & 0 & 0 & 0 \\
0 & 0 & 0 & 1
\end{array}\right]^{\mathrm{T}},
\end{gathered}
$$

According to the Equation (11), the control problem can be stated as the optimization of the four evaluation indexes by solving the introduced variables, $K_{d}, C_{d}, f_{s}$, and $f_{d}$.

\section{Coordination Control of the DVA and Suspension}

In order to achieve a significant vibration suppression performance, the coordination control of the proposed DVA and suspension is addressed in this section. First, the DVA parameters, $K_{d}$ and $C_{d}$, are optimally matched such that the DVA can passively isolate the electric wheel vibration. 
What is more, the DVA actuator force $f_{d}$ is controlled to further suppress the vibration. In addition, the suspension actuator is meanwhile controlled to actively reduce the sprung mass vibration.

\subsection{Parameters Optimization of the DVA}

Various parameter optimization methods are developed for vehicle suspension [42,43]. Whereas, most of the existing methods are not very suitable for the in-wheel DVA due to the special structure and the complicated constraints. The particle swarm optimization (PSO) algorithm is a nonlinear global optimization method, which features a fast convergence speed, a good robustness, and the least sensitivity to the number of variables, and is very effective to solve the multi-objective optimization problems with constraint conditions [44]. Thus, the PSO algorithm is adopted to optimize the DVA stiffness $K_{d}$ and damping $C_{d}$.

The parameter optimization process based on the PSO is shown in Figure 6. In the PSO algorithm, a group of random particles based on the model simulations are initialized. Comprehensive analysis between the individual particle and the group particles can dynamically update their velocity and position. Through continuous iteration, the particles optimization problem can be solved.

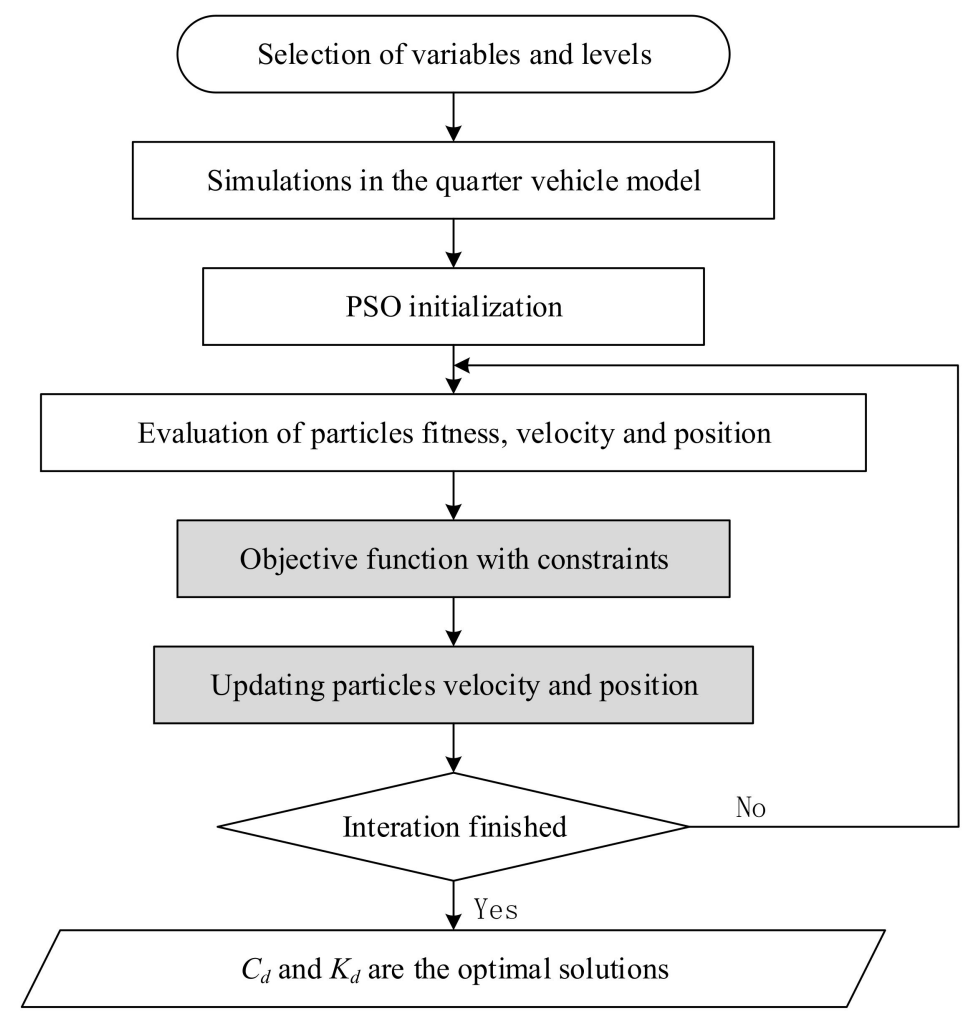

Figure 6. Parameter optimization process based on the PSO.

\section{(1) Objective function with constraints}

The optimization goal of the DVA is to reduce electric wheel vibration, which is evaluated by using four indexes, the SVA, SDD, TDL, and MVW. Therefore, the objective function can be expressed as

$$
\min J\left(K_{d}, C_{d}\right)=w_{S V A 1} \frac{R M S\left(a_{s D V A}\right)}{R M S\left(a_{s c o n}\right)}+w_{S D D 1} \frac{R M S\left(d_{s D V A}\right)}{R M S\left(d_{s c o n}\right)}+w_{T D L 1} \frac{R M S\left(F_{w D V A}\right)}{R M S\left(F_{w c o n}\right)}+w_{M V W 1} \frac{R M S\left(F_{e D V A}\right)}{R M S\left(F_{e c o n}\right)}
$$

where $a_{S D V A}, d_{s D V A}, F_{w D V A}$, and $F_{e D V A}$ are the expression of the four evaluation indexes in the electric wheel with the DVA, given by Equations (6)-(9). $a_{\text {scon }}, d_{s c o n}, F_{w c o n}$, and $F_{e c o n}$ are those in the conventional electric wheel. $R M S(\theta)$ stands for the root mean square values of signal $\theta$, which can reduce the random influences in a certain extent. In addition, $w_{S V A 1}, w_{S D D 1}, w_{T D L 1}$ and $w_{M V W 1}$ are 
the penalty factors for each of the four indexes, and $w_{S V A 1}+w_{S D D 1}+w_{T D L 1}+w_{M V W 1}=1$. The ride comfort and motor dynamic force are considered more crucial than the suspension deflection and wheel load, thus the four penalty factors are set to:

$$
w_{S V A 1}=0.3, \quad w_{S D D 1}=0.15, \quad w_{T D L 1}=0.15, \quad w_{M V W 1}=0.4
$$

In the optimization process, the parameters and variables in the objective function should satisfy several constraints. In order to ensure the road holding performance, the probability of the wheel jump should be less than $0.15 \%$, and the collision probability between the suspension frame and the limit block should be within $0.135 \%$. Besides, the vertical displacement between the motor rotor and the wheel rim, guided by the translation pair, should be constrained as well. Therefore, the variables constraints are expressed as:

$$
\left\{\begin{array}{l}
R M S\left(F_{w D V A}\right) \leq G / 3 \\
R M S\left(d_{s D V A}\right) \leq\left[d_{s}\right] / 3 \\
\max \left|x_{e}-x_{w}\right| \leq 12 \mathrm{~mm} \\
R M S\left(x_{e}-x_{w}\right) \leq 4 \mathrm{~mm}
\end{array}\right.
$$

where $G$ is the tire static load, and $\left[d_{s}\right]$ represents the suspension limited travel.

In addition, the DVA is paralleled with vehicle suspension, which changes vehicle vibration characteristics. In order to ensure the suspension performance, the relative damping coefficient and the natural frequency of the sprung mass are constrained in the range of $[0.2,0.4]$ and $[1,1.5]$, respectively. And the relative damping coefficient of the motor is set in the range of $[0.2,0.4]$ as well. That is:

$$
\left\{\begin{array}{c}
\xi_{s}\left(K_{d}\right)=\frac{C_{s}}{2 \sqrt{m_{s}\left(K_{s}+K_{d}\right)}} \in[0.2,0.4] \\
\omega_{s}\left(K_{d}\right)=\frac{1}{2 \pi} \sqrt{\frac{K_{s}+K_{d}}{m_{s}}} \in[1,1.5] \\
\xi_{e}\left(C_{d}, K_{d}\right)=\frac{C_{d}}{2 \sqrt{K_{d} \cdot m_{e}}} \in[0.2,0.4]
\end{array}\right.
$$

where $\xi_{s}$ and $\omega_{s}$ represent the relative damping coefficient and the natural frequency of the sprung mass, respectively. $\xi_{e}$ represents the relative damping coefficient of the motor.

\section{(2) Optimization solution by using the PSO algorithm}

The objective function with constraints can be optimally solved by using the PSO algorithm. In optimization process, a particle is, in each iteration, renewed through an individual extreme value and a global extreme value. The two extremes present the optimal solution of the particle itself and that of the whole population, respectively. Based on the two extremes, particle's velocity and position can be updated according to:

$$
\begin{gathered}
v_{i j}^{k+1}=W_{k} \cdot v_{i j}^{k}+r_{1} \cdot c_{1} \cdot\left(p_{\text {best }}^{k} \underset{i j}{k}-x_{i j}^{k}\right)+r_{2} \cdot c_{2} \cdot\left(g_{\text {best }}^{k+1}-x_{i j}^{k}\right) \\
x_{i j}^{k+1}=x_{i j}^{k}+v_{i j}^{k+1}
\end{gathered}
$$

where $v_{i j}$ represents the $j$-dimensional velocity of the $i$ th particle given by $\left|v_{i j}\right| \leq v_{i j \max }$, and $x_{i j}$ is the $j$-dimensional position of the $i$ th particle given by $\left|x_{i j}\right| \leq x_{i j \text { max }}$. $p_{\text {best } i j}$ and $g_{\text {best } i j}$ are the $j$-dimensional individual extremum position and the $j$-dimensional global extremum position of the $i$ th particle, respectively. $k$ is the iteration number. $c_{1}$ and $c_{2}$ are the coefficients studied and both of them are set to 2 , and $r_{1}$ and $r_{2}$ are random numbers between 0 and $1 . W_{k}$ is the inertia weighting factor, which determines the search ability of the particles, and influences an oscillating phenomenon in the global and local optimization solutions. 
In this study, the inertia weighting factor $W_{k}$ is adjusted by employing a nonlinear decreasing method, whereby the inertia weighting factor $W_{k}$ is nonlinear reduced from the maximum value $W_{\max }$ to the minimum value $W_{\min }$, according to:

$$
W_{k}=W_{\min }+\left(W_{\max }-W_{\min }\right) \cdot \tan \left(0.875 \cdot\left(1-\sqrt{k / k_{\max }}\right)\right)
$$

where $k_{\max }$ represents the maximum iteration number. The constant of 0.875 is to ensure that $W_{k}$ varies in the range of $\left[W_{\min }, W_{\max }\right] . W_{\max }$ and $W_{\min }$ are set to 0.9 and 0.4 , respectively.

By applying the above PSO algorithm to the objective function with constraints, expressed as Equations (12), (14), and (15), the optimal DVA parameters, $K_{d}$ and $C_{d}$, can be found.

\subsection{DVA Actuator Force Control}

The DVA with matched parameters behaves just like a passive vibration absorber, and it is difficult to exploit it to achieve an optimum performance due to the complicated road excitation and environmental disturbance. In the proposed DVA, an actuator force can be adaptively controlled to further suppress motor vibration. It is worthwhile to note that this study focuses on the control of the actuator force for vibration suppression, rather than the realization of the controlled force of the practical actuators, which differs in different types of actuators. However, from the application perspective, the disturbance and noise of actuators should be taken into consideration. Regardless the specific types of practical actuators, the fuzzy control method is independent on the exact model, and is adopted to control the DVA actuator force with the disturbance and noise in this section.

To address the trade-off between the quantity of fuzzy rules and precision of the conventional constant-domain-based fuzzy control method, we design an alterable-domain-based fuzzy control method, in which the inputs and outputs domains are alterable by using the scaling factors as:

$$
\left\{\begin{array}{l}
X_{i}=\left[-s_{i}\left(x_{i}\right) \cdot E_{i}, s_{i}\left(x_{i}\right) \cdot E_{i}\right] \\
Y_{i}=\left[-s_{i}\left(y_{i}\right) \cdot U_{i}, s_{i}\left(y_{i}\right) \cdot U_{i}\right] \\
s_{i}\left(x_{i}\right), s_{i}\left(y_{i}\right) \in[0,1]
\end{array}\right.
$$

where $\left[-E_{i}, E_{i}\right]$ and $\left[-U_{i}, U_{i}\right]$ are the basic domains of the inputs $x_{i}$ and outputs $y_{i}$, respectively. $s_{i}\left(x_{i}\right)$ and $s_{i}\left(y_{i}\right)$ are the scaling factors for altering the inputs and output domains, respectively, and they are determined based on fuzzy rules as well. The alterable-domain-based fuzzy controller is beneficial to adaptively improve the control precision and simply fuzzy rules.

The alterable-domain-based fuzzy method for the DVA actuator force control is designed as shown in Figure 7. The fuzzy controller I is designed to determine the scaling factors of the inputs and outs domains, which takes the motor vertical acceleration $a_{e}$ and the relative vertical velocity $v_{r e}$ between the motor and rim as inputs, and takes the scaling factors, the $s_{a e}$ for the $a_{e}$, the $s_{v r e}$ for the $v_{r e}$, and the $s_{f d}$ for the actuator force $f_{d}$, as outputs. In the fuzzy controller II, the inputs are the $a_{e}$ and $v_{r e}$ with the altered domains and the $s_{f d}$, and the output is the DVA actuator force $f_{d}$. The fuzzy rules and parameters of the fuzzy controllers are determined as follows:

(1) The rules for the $s_{a e}$ and $s_{v r e}$ are determined based on the $a_{e}$ and $v_{r e}$, respectively. Large values of the $a_{e}$ and $v_{r e}$ correspond to large values of the $s_{a e}$ and $s_{v r e}$ to enhance the control intensity and suppress the overshoot. Small values of the $a_{e}$ and $v_{r e}$ correspond to small values of the $s_{a e}$ and $s_{\text {vre }}$ to narrow the domains and ensure the rule quantity, whereby the trade-off between the rule quantity and the control precision is well balanced.

(2) The rules for the $s_{f d}$ are determined based on both the $a_{e}$ and $v_{r e}$. If both the $a_{e}$ and $v_{r e}$ move in the same direction with large values, the $s_{f d}$ is set to a large value to suppress the vibration. If the $a_{e}$ and $v_{r e}$ move in the opposite direction, the system is adaptive to gradually converge, so the $s_{f d}$ is set to a relatively small value. In addition, if the $a_{e}$ is a large value while the $v_{r e}$ is a small value, the $s_{f d}$ is set to a relatively large value to prevent the system from the vibration divergence. 
(3) For the fuzzy controller I and II, the basic domains of the $a_{e}, v_{r e}$, and $f_{d}$ are set to [-10, 10], $[-2,2]$ and $[-200,200]$, respectively, and their fuzzy domains are all set to $[-6,6]$. In addition, the quantization factors are set to $k_{a e}=0.6, k_{v r e}=3$, and $k_{f d}=33$.

(4) For the scaling factors, the basic domains of the $s_{a e}$, $s_{v r e}$, and $s_{f d}$ are all set to [0,1], and their fuzzy domains are set to $[0,1]$ as well.

(5) The values of $a_{e}, v_{r e}$, and $f_{d}$ are classed as seven fuzzy subsets, i.e., Positive Large (PL), Positive Medium (PM), Positive Small (PS), Zero (Z), Negative Small (NS), Negative Medium (NM), and Negative Large (NL).

(6) The values of $s_{a e}$ and $s_{\text {vre }}$ are classed as four fuzzy subsets, Zero (Z), Small (S), Medium (M), and Large (L). While the values of $s_{f d}$ are classed as seven fuzzy subsets, Zero (Z), Very Small (VS), Small (S), Relatively Small (RS), Medium (M), Large (L), and Very Large (VL).

(7) All fuzzy subsets' membership functions are selected as triangular functions.

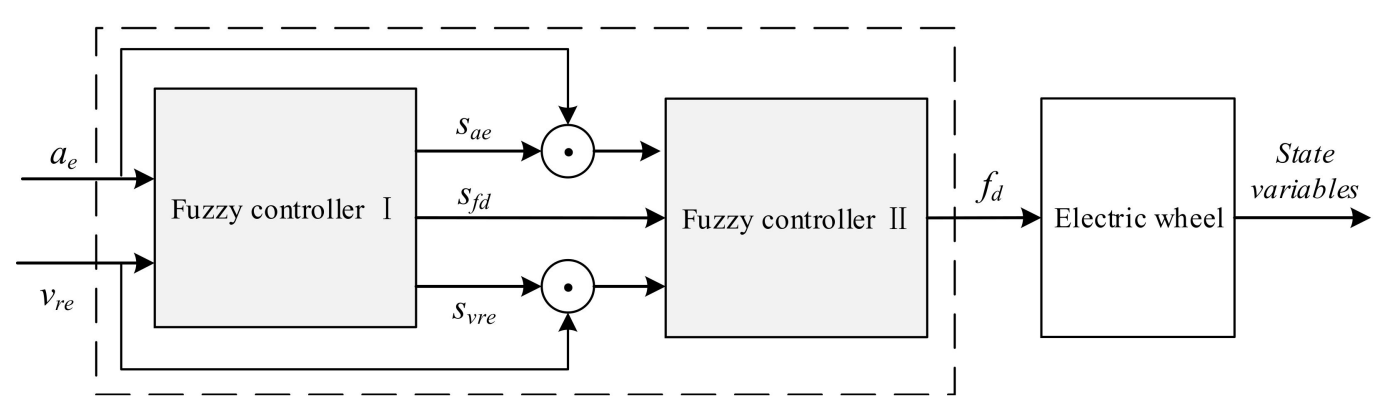

Figure 7. Alterable-domain-based fuzzy method for DVA actuator force control.

By applying the above settings in comprehensive simulations, we establish the same fuzzy rules for $s_{a e}$ and $s_{v r e}$ as shown in Table 1, the fuzzy rules for $s_{f d}$ as shown in Table 2, and the fuzzy rules for $f_{d}$ as shown in Table 3. The corresponding fuzzy surfaces are shown in Figure 8a-d.

Table 1. Fuzzy rules for $s_{a e}$ and $s_{v r e}$.

\begin{tabular}{cccccccc}
\hline$a_{e}$ or $v_{r e}$ & NL & NM & NS & Z & PS & PM & PL \\
\hline$s_{a e}$ or $s_{\text {vre }}$ & $\mathrm{L}$ & $\mathrm{M}$ & $\mathrm{S}$ & $\mathrm{Z}$ & $\mathrm{S}$ & $\mathrm{M}$ & $\mathrm{L}$ \\
\hline
\end{tabular}

Table 2. Fuzzy rules for $s_{f d}$.

\begin{tabular}{cccccccc}
\hline \multirow{2}{*}{$v_{r e}$} & \multicolumn{7}{c}{$\boldsymbol{a}_{\boldsymbol{e}}$} \\
\cline { 2 - 8 } & NL & NM & NS & Z & PS & PM & PL \\
\hline NL & VL & VL & L & L & M & S & VS \\
NM & VL & M & L & M & VS & S & VS \\
NS & S & RS & M & Z & M & RS & S \\
Z & VS & S & VS & M & L & M & VL \\
PS & VS & S & M & L & L & VL & VL \\
PM & Z & S & RS & VL & VL & VL & VL \\
PL & VL & VL & L & L & M & S & VS \\
\hline
\end{tabular}


Table 3. Fuzzy rules for $f_{d}$.

\begin{tabular}{cccccccc}
\hline \multirow{2}{*}{$v_{r e}$} & \multicolumn{7}{c}{$\boldsymbol{a}_{\boldsymbol{e}}$} \\
\cline { 2 - 7 } & $\mathbf{N L}$ & NM & NS & $\mathbf{Z}$ & PS & PM & PL \\
\hline NL & PL & PL & PL & PL & PM & Z & Z \\
NM & PL & PL & PL & PL & PM & Z & Z \\
NS & PM & PM & PM & PM & Z & NS & NS \\
Z & PM & PM & PS & Z & NM & NM & NM \\
PS & PS & PS & Z & NM & NM & NM & NM \\
PM & Z & Z & NM & NL & NL & NL & NL \\
PL & Z & Z & NM & NL & NL & NL & NL \\
\hline
\end{tabular}

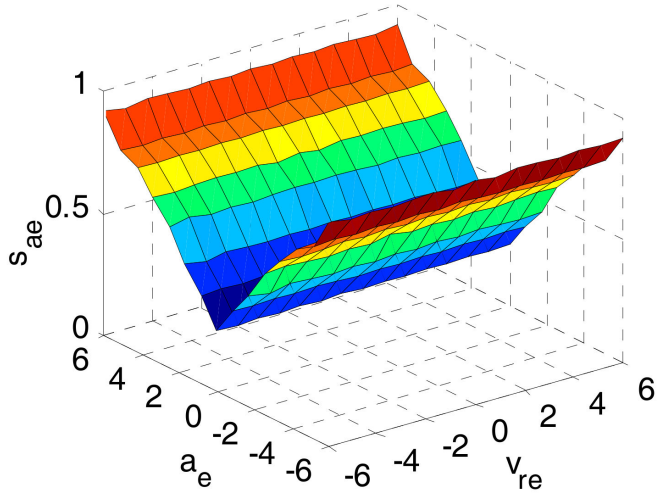

(a)

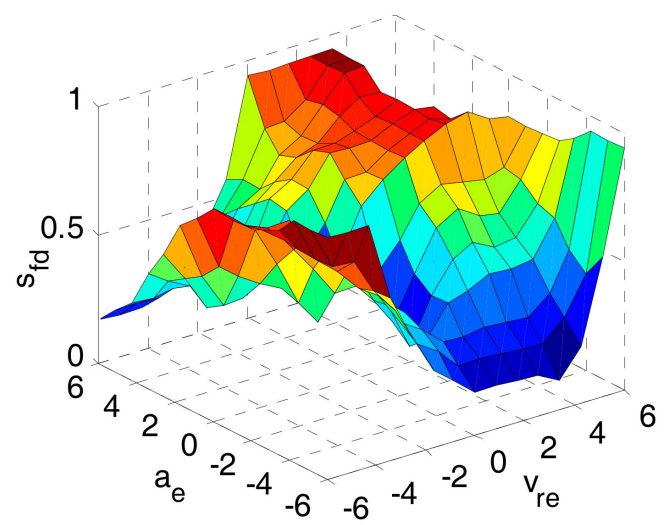

(c)

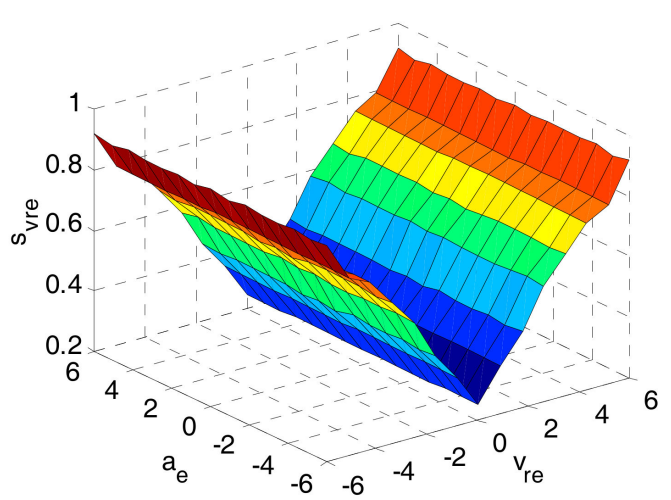

(b)

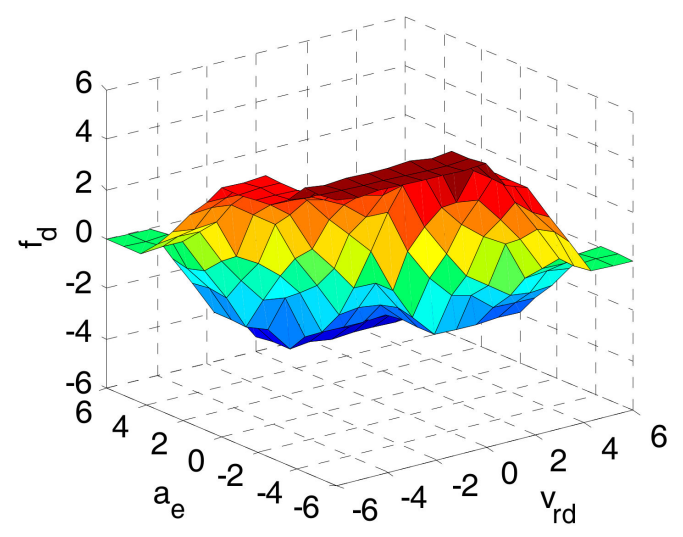

(d)

Figure 8. Fuzzy surfaces for: (a) $s_{a e} ;$ (b) $s_{v r e} ;$ (c) $s_{f d}$; and (d) $f_{d}$.

\subsection{Suspension Actuator Force Control}

The DVA system proposed above is paralleled with vehicle suspension, changing vehicle vibration characteristics. That weakens the original suspension performance and deteriorates the sprung mass vibration. Thus, appropriately control of the suspension is necessary. In this section, the linear quadratic regulator (LQR) algorithm, widely used in active and semi-active suspension control, is adopted to control the suspension actuator force to improve vehicle ride comfort. 
Addressing the suspension actuator force control, we rewrite the Equation (11) as the linear state space equations with only one control variable, i.e., the suspension actuator force $u_{1}=f_{s}$. That is

$$
\left\{\begin{array}{l}
\dot{x}=\mathbf{A} x+\mathbf{B}_{1} u_{1}+\mathbf{G} w \\
y=\mathbf{C} x+\mathbf{D}_{1} u_{1}
\end{array}\right.
$$

where:

$$
\begin{gathered}
\mathbf{B}_{1}=\left[\begin{array}{cccccc}
-1 / m_{w} & 0 & 1 / m_{s} & 0 & 0 & 0
\end{array}\right]^{\mathrm{T}}, \\
\mathbf{D}_{1}=\left[\begin{array}{cccc}
1 / m_{s} & 0 & 0 & 0
\end{array}\right]^{\mathrm{T}}, \\
u_{1}=f_{s} .
\end{gathered}
$$

and the other symbols are the same as those in Section 3.

The standard LQR method for the state space Equation (20) can be stated as:

$$
\min J=\frac{1}{2} \int_{0}^{\infty}\left(x^{\mathrm{T}} \mathbf{Q} x+u_{1}{ }^{\mathrm{T}} \mathbf{R} u_{1}+2 x^{\mathrm{T}} \mathbf{N} u_{1}\right) d t
$$

where $J$ is a quadratic performance index. $\mathbf{Q}$ is a positive definite weighting matrix of the state variables $x$, and $\mathbf{R}$ is a positive definite weighting matrix of the control variable $u_{1}$. $\mathbf{N}$ is the associated matrix of the $\mathbf{Q}$ and $\mathbf{R}$. There is an optimal control variable $u_{1}$, based on the state variables feedback, to minimize the index $J$. That is:

$$
u_{1}(t)=-\mathbf{K} x
$$

where $\mathbf{K}$ is the state feedback gain matrix, and can be solved from the Riccati equation, based on the LQR method, as:

$$
\mathbf{A K}+\mathbf{K A}^{\mathrm{T}}+\mathbf{Q}-\mathbf{K B R}^{-1} \mathbf{B}_{1}{ }^{\mathrm{T}} \mathbf{K}+\mathbf{G} w \mathbf{G}^{\mathrm{T}}=0
$$

Using the LQR function in the Matlab software, we can solve the Riccati Equation (22) as:

$$
\mathbf{K}=\operatorname{LQR}\left(\begin{array}{lllll}
\mathbf{A}, & \mathbf{B}_{1}, & \mathbf{Q}, & \mathbf{R}, & \mathbf{N}
\end{array}\right)
$$

For the suspension actuator force control, the objective is to improve the ride comfort, which is evaluated by the output variables $y$ in Equation (20), i.e., the SVA, SDD, TDL, and MVW. Therefore, we define the quadratic performance index $J$ as:

$$
\min J=\frac{1}{2} \int_{0}^{\infty}\left(q_{1} a_{s}^{2}+q_{2} d_{s}^{2}+q_{3} F_{w}^{2}+q_{4} F_{d}^{2}\right) \mathrm{d} t
$$

where $q_{1}, q_{2}, q_{3}, q_{4}$ are the weighing factors of the SVA, SDD, TDL, and MVW, respectively. Further, the weighting matrixes $\mathbf{Q}, \mathbf{R}$, and $\mathbf{N}$ can be deduced as:

$$
\left\{\begin{array}{l}
\mathbf{Q}=\mathbf{C}^{\mathrm{T}} \mathbf{Q}_{p} \mathbf{C} \\
\mathbf{R}=\mathbf{D}_{1}^{\mathrm{T}} \mathbf{Q}_{p} \mathbf{D}_{1} \\
\mathbf{N}=\mathbf{C}^{\mathrm{T}} \mathbf{Q}_{p} \mathbf{D}_{1} \\
\mathbf{Q}_{p}=\operatorname{diag}\left(q_{1}, q_{2}, q_{3}, q_{4}\right)
\end{array}\right.
$$

The aforementioned optimizing procedure is applied to Equations (25) and (26) such that the optimal controlled force $u_{1}$ can be solved.

Notably, the weighting factors, $q_{1}, q_{2}, q_{3}, q_{4}$, enormously influence the control effectiveness. The suspension performance may be worse than passive ones in some frequency bands, if these weighting factors are selected improperly. The PSO algorithm introduced in Section 4.1 is used to determine the optimal weighting factors. 
Similar to the Equation (12), we define an objective function as:

$$
\min J\left(q_{i}\right)=w_{S V A 2} \frac{R M S\left(a_{s s u s}\right)}{\operatorname{RMS}\left(a_{s D V A}\right)}+w_{S D D 2} \frac{R M S\left(d_{s u s}\right)}{\operatorname{RMS}\left(d_{s D V A}\right)}+w_{T D L 2} \frac{R M S\left(F_{w u s s}\right)}{\operatorname{RMS}\left(F_{w D V A}\right)}+w_{M V W 2} \frac{R M S\left(F_{e s u s}\right)}{\operatorname{RMS}\left(F_{e D V A}\right)}
$$

where $i=1,2,3,4 . a_{s s u s}, d_{s s u s}, F_{w s u s}$, and $F_{\text {esus }}$ are the expression of the four evaluation indexes in the electric wheel with the LQR-based suspension control. $w_{S V A 2}, w_{S D D 2}, w_{T D L 2}$, and $w_{M V W 2}$ are the penalty factors for each of the four indexes, and they are set to:

$$
w_{S V A 2}=0.4, \quad w_{S D D 2}=0.15, \quad w_{T D L 2}=0.15, \quad w_{M V W 2}=0.3
$$

The optimization procedure of $q_{1}, q_{2}, q_{3}$, and $q_{4}$ is similar to that of the parameters optimization in Section 4.1.

\section{Simulation Investigation}

\subsection{Simulation Parameters}

A quarter-vehicle model of an A-class vehicle with the conventional electric wheel, as shown in Figure $5 \mathrm{a}$, is chosen as the benchmarked model. In order to verify the superiority of the proposed electric wheel and control methods, other four models of quarter-vehicle are conducted as comparisons. The five schemes of the quarter-vehicle models are shown in Table 4. These schemes differ in terms of the electric wheel configuration, DVA control method and suspension control method. Notably, the fuzzy control in DC1-SC is with alterable domains proposed in this study, while the fuzzy control in DC2-SC is with constant domains proposed in [45].

Table 4. Quarter-vehicle models with different electric wheels.

\begin{tabular}{cccc}
\hline Model Marked & Electric Wheel & DVA Control & Suspention Control \\
\hline C-NC & Benchmarked Conventional & No control & No control \\
D-NC & DVA & No control & No control \\
D-SC & DVA & No control & LQR control \\
DC1-SC & DVA & Fuzzy control with alterable domins & LQR control \\
DC2-SC & DVA & Fuzzy control with constant domins & LQR control \\
\hline
\end{tabular}

* The fuzzy control in DC1-SC is with alterable domains proposed in this study. ${ }^{* *}$ The fuzzy control in DC2-SC is with constant domains proposed in [45].

The parameters of the five models are shown in Table 5. In the Table 5, the DVA parameters $K_{d}$ and $C_{d}$ in Section 4.1 and the LQR weighting parameters $q_{i}(i=1,2,3,4)$ in Section 4.3 are optimized by using the PSO algorithm. Since the most national road conditions in China are B-class level or C-class level, and the vehicle speeds on these roads are normally between $60 \mathrm{~km} / \mathrm{h}$ and $80 \mathrm{~km} / \mathrm{h}$, the parameters optimization is carried out under the typical conditions of the C-class pavement at a speed of $70 \mathrm{~km} / \mathrm{h}$, and the optimized parameters are as follows:

$$
\left\{\begin{array}{l}
K_{d}=8025 \mathrm{~N} / \mathrm{m}, \quad C_{d}=480 \mathrm{~N} \cdot \mathrm{s} / \mathrm{m} \\
q_{1}=6.09, \quad q_{2}=8492, \quad q_{3}=0.0000146, \quad q_{4}=0.0000574
\end{array}\right.
$$

Simulations under the random road excitation and bump road excitation are conducted on the five quarter-vehicle models, by using the Matlab/Simulink software. In the simulations, we evaluate the control effectiveness based on the four evaluation indexes given by Equations (6)-(9), SVA, MVW, SDD, and TDL. The four indexes are measured relative to the static positions, thus their initial values are considered as zero, and their boundary conditions are given by Equations (14) and (15). In addition, the longitudinal and lateral force of the vehicle and tire are ignored, and we assume that only the tire, electric wheel and sprung mass have the degree of vertical translational freedoms. 
Table 5. Parameters of the quarter-vehicle models.

\begin{tabular}{ccc}
\hline Parameters & C-NC & D-NC/D-SC/DC1-SC/DC2-SC * \\
\hline sprung mass $m_{s}(\mathrm{~kg})$ & 292 & 292 \\
Suspension stiffness $K_{s}(\mathrm{~N} / \mathrm{m})$ & 17,000 & 17,000 \\
Suspension damping $C_{s}(\mathrm{~N} \cdot \mathrm{s} / \mathrm{m})$ & 1317 & 1317 \\
Vertical stiffness of tire $K_{t}(\mathrm{~N} / \mathrm{m})$ & 241,600 & 241,600 \\
Tire mass $m_{t}(\mathrm{~kg})$ & 40 & 40 \\
Motor Mass $m_{e}=m_{e}+m_{e 2}(\mathrm{~kg}) * *$ & 45 & 45 \\
suspension limited travel $\left[d_{s}\right](\mathrm{m})$ & 0.08 & 0.08 \\
DVA spring stiffness $K_{d}(\mathrm{~N} / \mathrm{m})$ & - & 8025 \\
DVA damping $C_{d}(\mathrm{~N} \cdot \mathrm{s} / \mathrm{m})$ & - & 480
\end{tabular}

* The four models have the same parameters and the different control shemes. ${ }^{* *}$ The motor mass includes the wheel-reducer mass for the outer-rotor motor.

\subsection{Random Road Excitation}

In this simulation, a C-class road is introduced as the random road excitation, and the vehicle speed is set to a constant value of $70 \mathrm{~km} / \mathrm{h}$. The profile of the C-class road is shown in Figure 9 . In addition, in order to verify the robust performance of the proposed method, a band-limited white noise is introduced to the actuator force of both the suspension and DVA. The noise is in the range of $20 \%$ of the actuator force, which is shown in Figure 10.

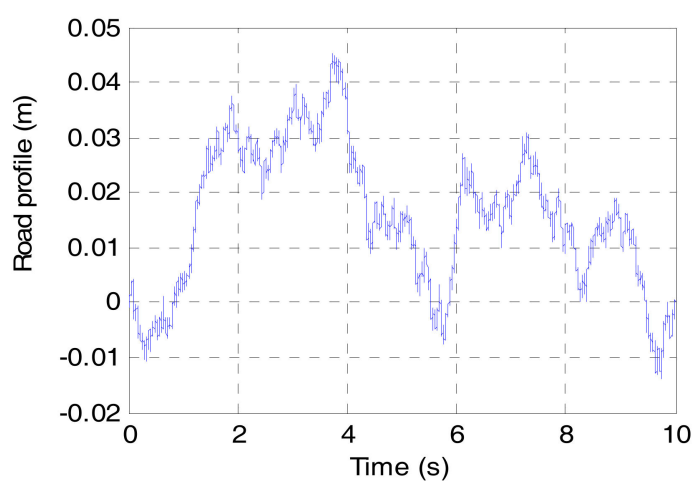

Figure 9. Profile of the C-class road.

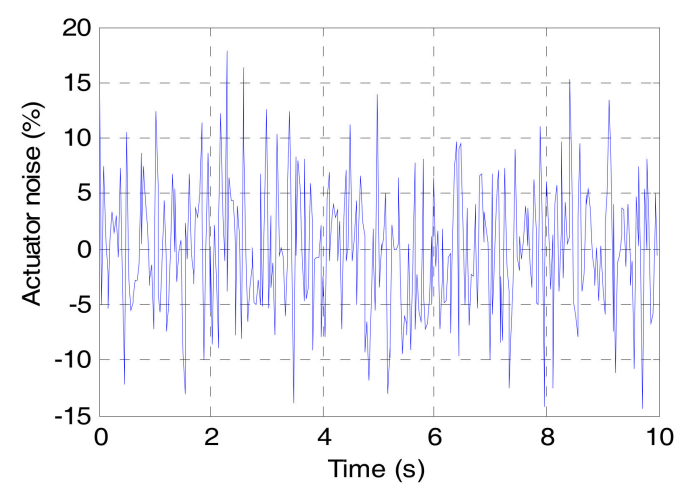

Figure 10. Actuator noise.

Figures 11-14 show the responses of the four evaluation indexes, i.e., the sprung mass vertical acceleration (SVA), motor vertical wallop (MVW), suspension dynamic deflection (SDD), and tire dynamics load (TDL), in the time domain. The peak value and RMS value of the four evaluation indexes are presented as well. 


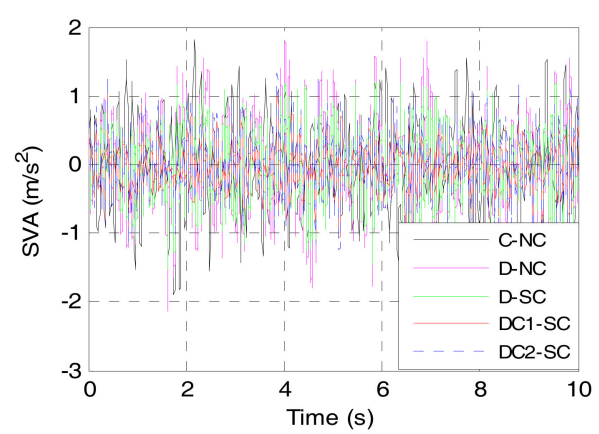

(a)

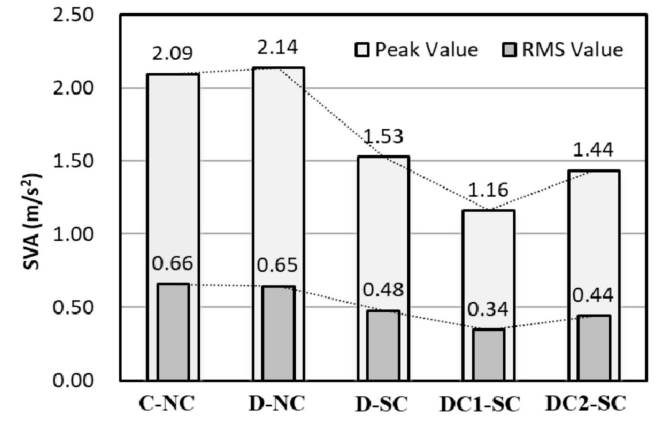

(b)

Figure 11. Sprung mass vertical acceleration (SVA). (a) Responses in time domain; (b) Peak value and RMS value.

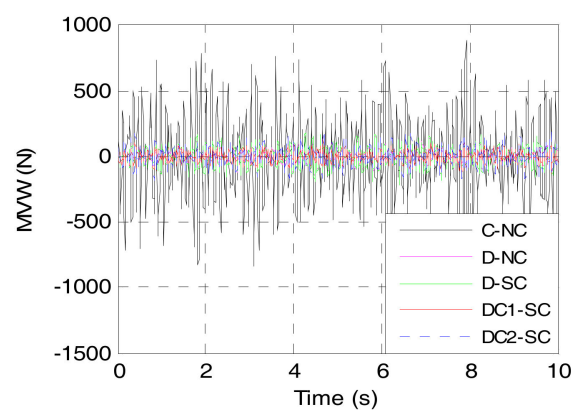

(a)

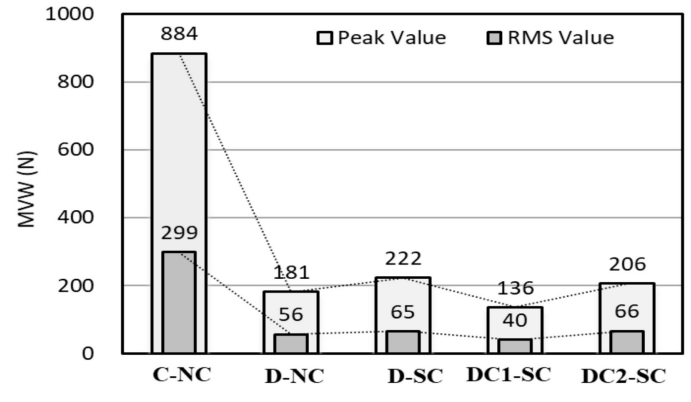

(b)

Figure 12. Motor vertical wallop (MVW). (a) Responses in the time domain; (b) Peak value and RMS value.

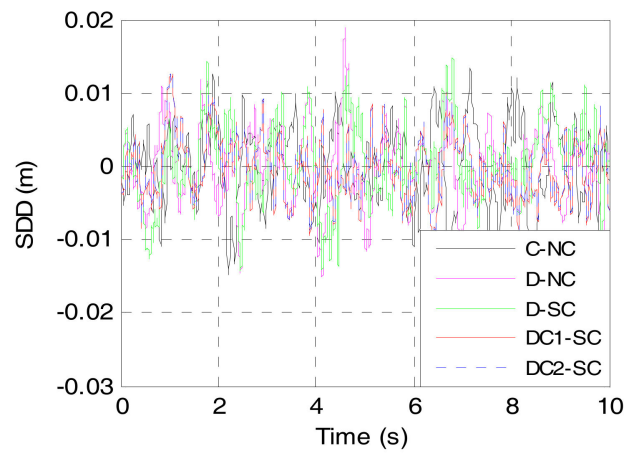

(a)

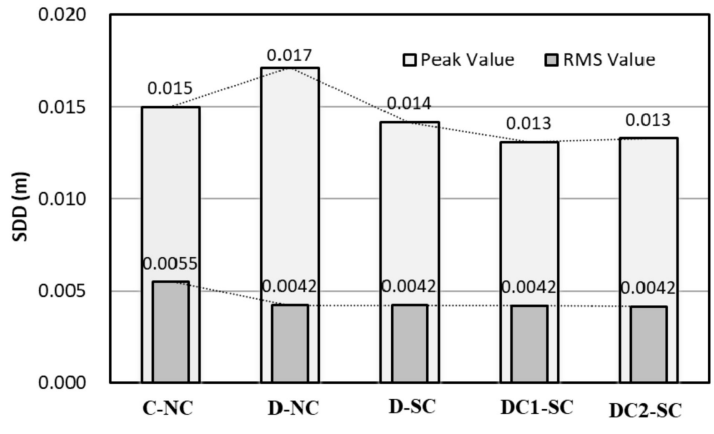

(b)

Figure 13. Suspension dynamic deflection (SDD). (a) Responses in the time domain; (b) Peak value and RMS value. 


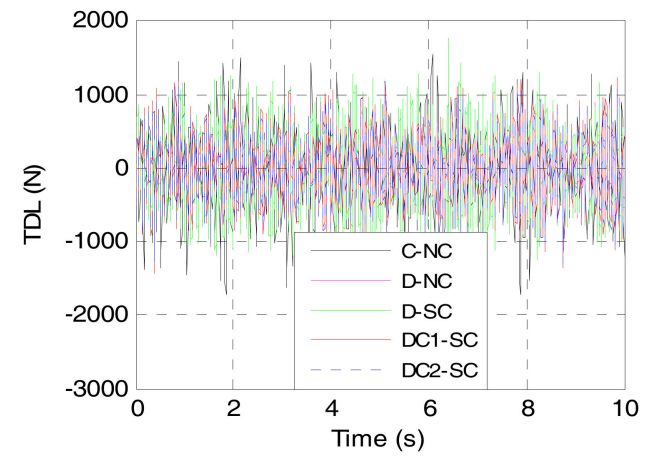

(a)

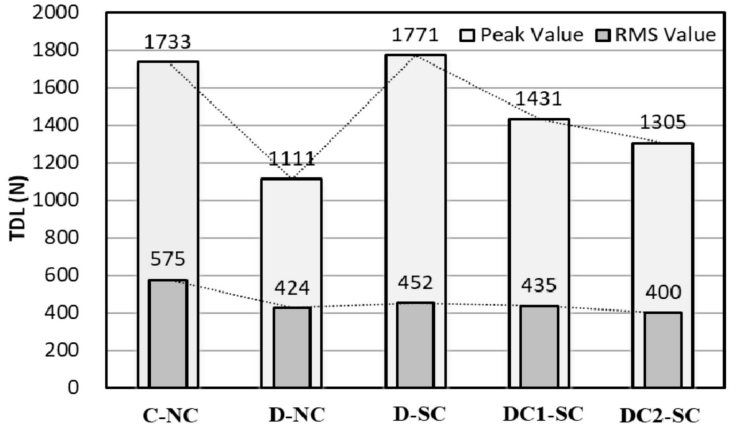

(b)

Figure 14. Tire dynamics load (TDL). (a) Responses in the time domain; (b) Peak value and RMS value.

Figure 11 shows the SVA responses of the five electric wheel schemes. The SVA of D-SC, DC1-SC, and DC2-SC is smaller than that of C-NC and D-NC, and the SVA of DC1-SC is the smallest. This indicates that the LQR control on suspension and the alterable-domain-based fuzzy control on DVA perform best for improving vehicle ride comfort. We can observe from Figure 12 that the MVW of D-NC, D-SC, DC1-SC, and DC2-SC is greatly reduced when compared to that of C-NC, meaning the DVA has a great effectiveness in the vibration suppression of electric wheel. Figure 13 presents that the SDD is no significant difference in the five electric wheel schemes, and the Figure 14 presents that the TDL of D-SC, DC1-SC, and DC2-SC performs even larger than that of D-NC. However, the SDD and TDL are maintained in the reasonable values.

Figure 15 shows the power spectral density (PSD) details of the four evaluation indexes responses in the frequency domain. From Figure 15a, we can see that the natural frequencies of the sprung mass and unsprung mass are both increased due to the introduction of the DVA, and the increased frequency-gap between the sprung mass and unsprung mass is beneficial to isolate the vehicle resonance. In addition, at the natural frequency band of the sprung mass $(1-2 \mathrm{~Hz})$, we can observe that compared with the SVA of C-NC, that of D-NC is even larger, and that of D-SC, DC1-SC, DC2-SC is much smaller. This indicates that the DVA, to a certain extent, deteriorates the vibration of sprung mass, while this negative effect can be eliminated and optimized by using the LQR-based suspension control.

Figure $15 \mathrm{~b}$ shows the PSD of the MVW and demonstrates the in-wheel vibration suppression effectiveness of the DVA. Compared with the MVW of C-NC, the MVW of the other four DVA-based electric wheels are greatly reduced. The enlarged view, at the natural frequency band of the unsprung mass $(10-12 \mathrm{~Hz})$, presents that the DC1-SC has the smallest MVW, demonstrating the effectiveness of the alterable-domain-based fuzzy controller. It is can be seen from Figure 15c,d that the DC1-SC exhibit excellent performance in the PSDs of the SDD and TDL, which guarantees the suspension performance and road holding performance.

Figure 16 shows the actuator force, including the suspension force and DVA force, in DC1-SC and DC2-SC. The suspension actuator force, shown in Figure 16a, is no much difference between DC1-SC and DC2-SC due to the similar LQR-based suspension control. Whereas, the DVA actuator force, shown in Figure 16b, differs greatly. The above results demonstrate that DC1-SC comprehensively performs better than DC2-SC, which benefits from the alterable-domain-based fuzzy method. It is worthwhile to note that the actuator force includes the noise shown in Figure 10, and the proposed control methods guarantee the good robustness of DC1-SC and DC2-SC. 


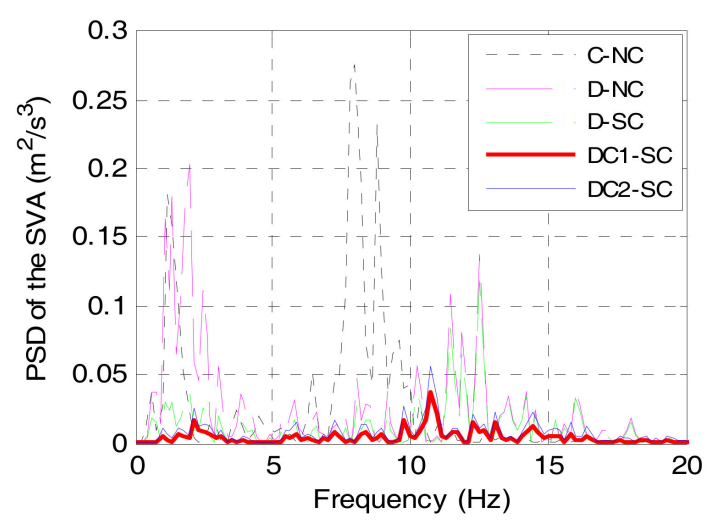

(a)

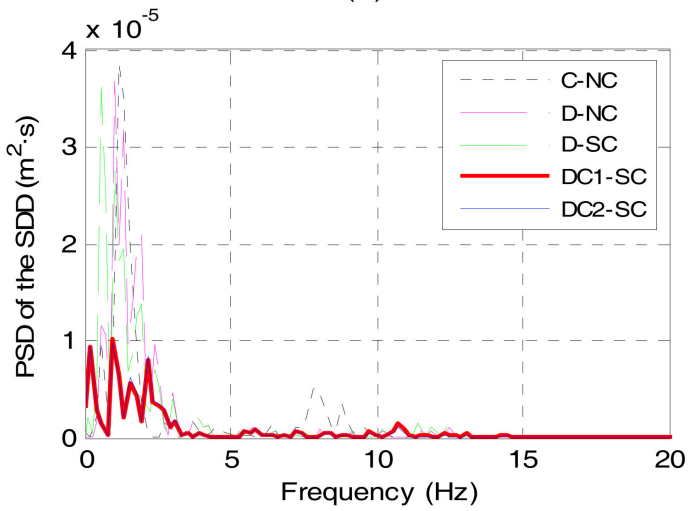

(c)

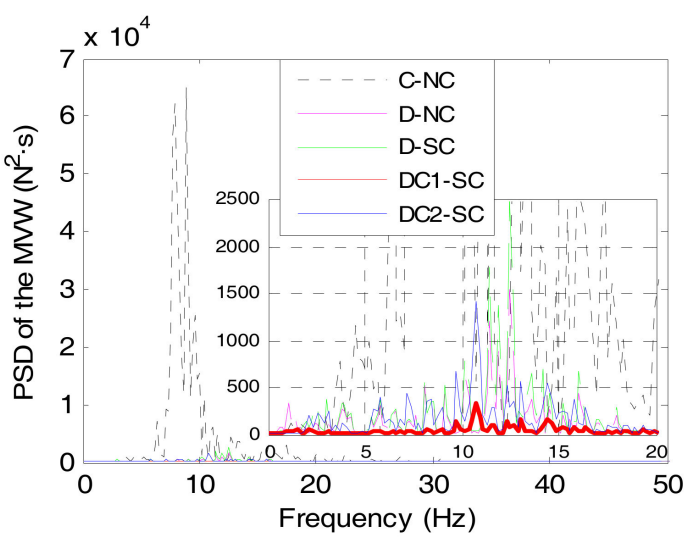

(b)

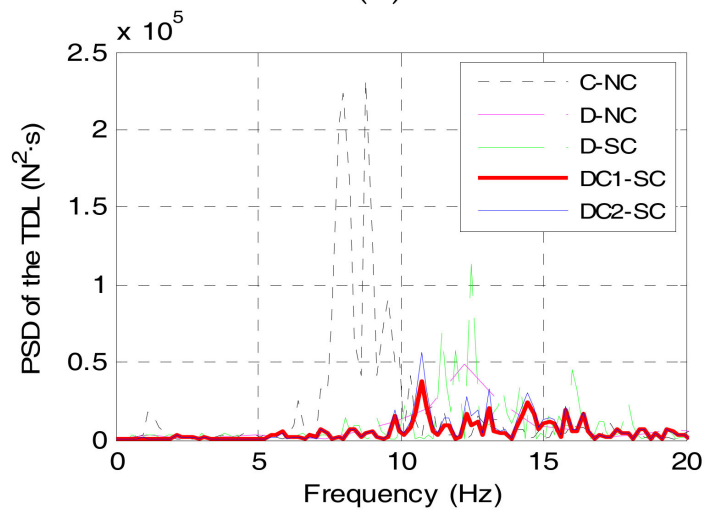

(d)

Figure 15. Power spectral density (PSD). (a) SVA; (b) MWV; (c) SDD; (d) TDL.

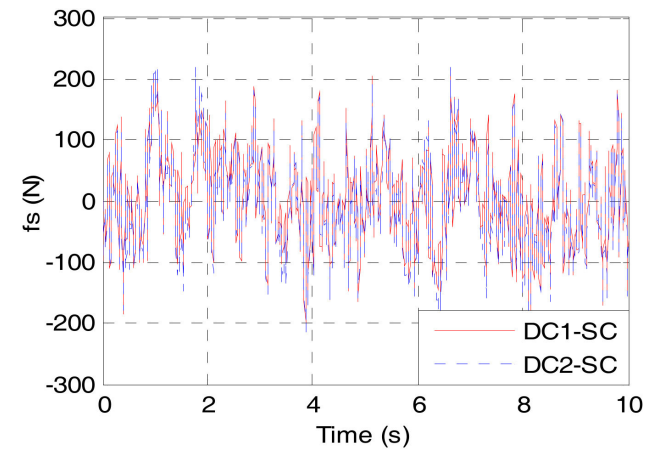

(a)

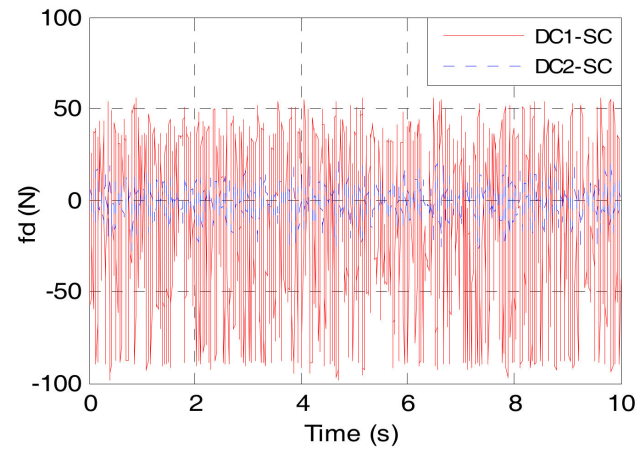

(b)

Figure 16. Actuator controlled force: (a) Suspension actuator force; (b) DVA actuator force.

\subsection{Bump Road Excitation}

In this simulation, a bump road excitation is set as a triangular bump with a height of $60 \mathrm{~mm}$ and a base of $400 \mathrm{~mm}$, as shown in Figure 17. Electric wheels cross the bump at a constant speed of $30 \mathrm{~km} / \mathrm{h}$. The four evaluation indexes responses with peak values and RMS values in the time domain are shown in Figures 18-21. 


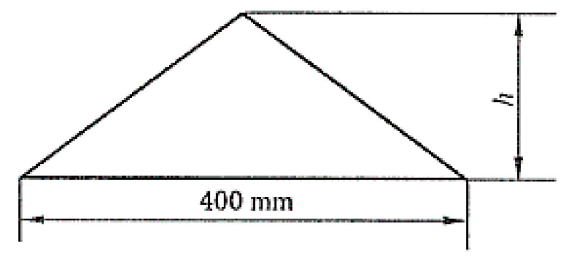

Figure 17. Schematic diagram of standard pulse pavement.

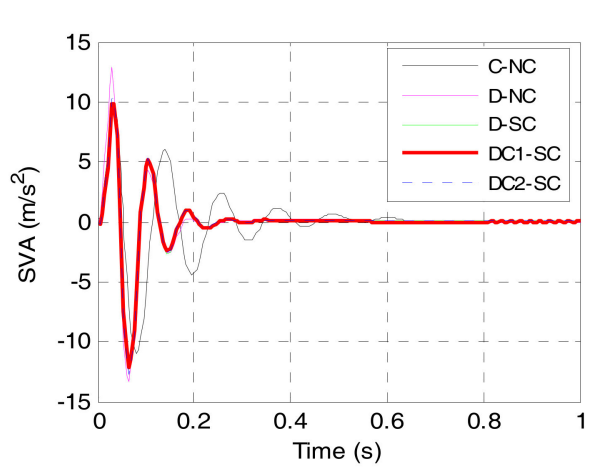

(a)

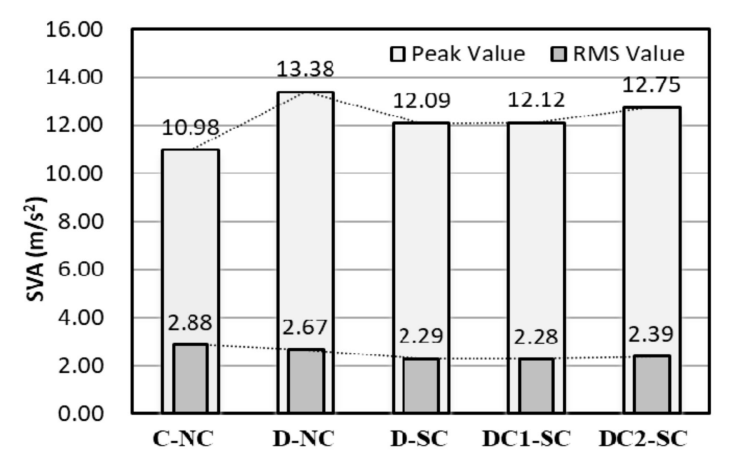

(b)

Figure 18. SVA responses. (a) Responses in time domain; (b) Peak value and RMS value.

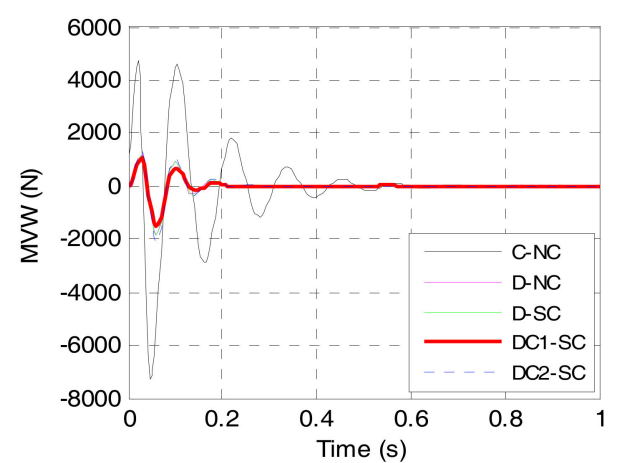

(a)

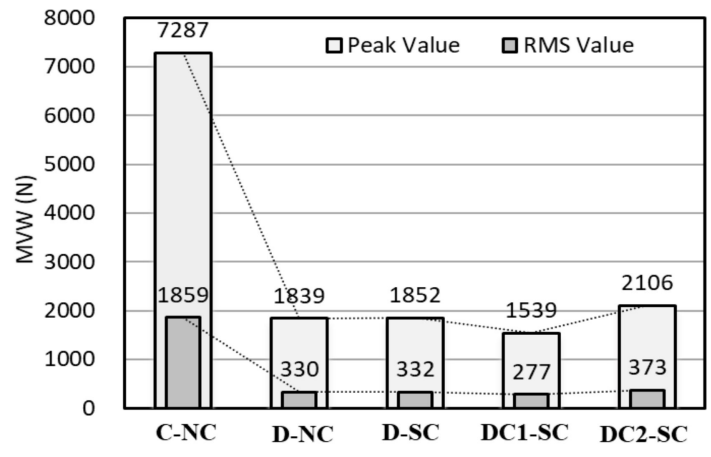

(b)

Figure 19. MWV responses. (a) Responses in time domain; (b) Peak value and RMS value.

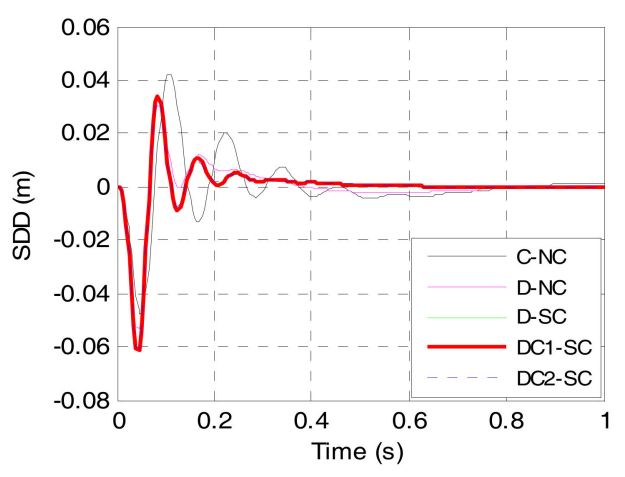

(a)

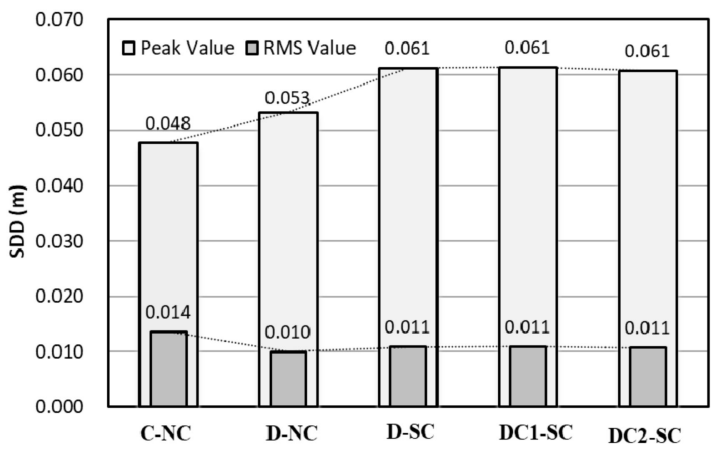

(b)

Figure 20. SDD responses. (a) Responses in time domain; (b) Peak value and RMS value. 


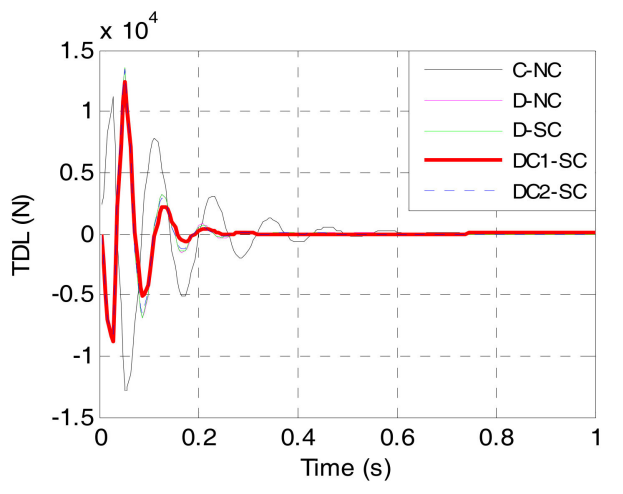

(a)

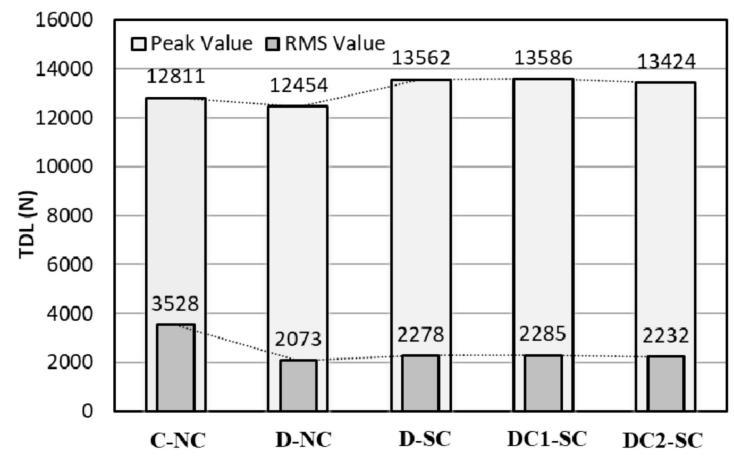

(b)

Figure 21. TDL responses. (a) Responses in time domain; (b) Peak value and RMS value.

Figure 18 shows the SVA responses of the five electric wheels. Compared with the peak value of C-NC, those of the other electric wheels are even larger, while the RMS values of the other four electric wheels are smaller. Especially, the DVA-based electric wheels converge more stably and quickly than C-NC. We can observe from Figure 19 that the MVW of the DVA-based electric wheels is greatly smaller than that of C-NC, and DC1-SC has the smallest MVW. This demonstrates that the DC1-SC exhibits the best performance on vehicle ride comfort and electric wheel vibration. Figures 20 and 21 show the SDD and TDL responses, respectively. It can be seen that the SDD and TDL of DC1-SC are not the smallest compared with those of the other electric wheels, but they are still maintained in the reasonable values.

Figure 22 presents the actuator force of suspension and DVA. In Figure 22b, The DVA force of DC1-SC lasts longer than that of DC2-SC, which ensures that DC1-SC performs more effectively in the vibration suppression.

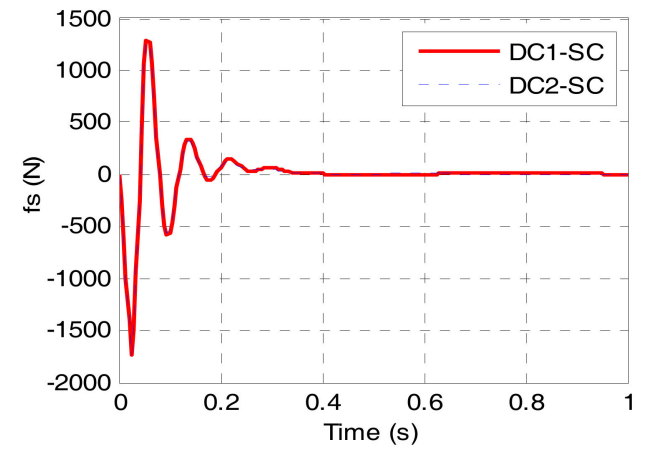

(a)

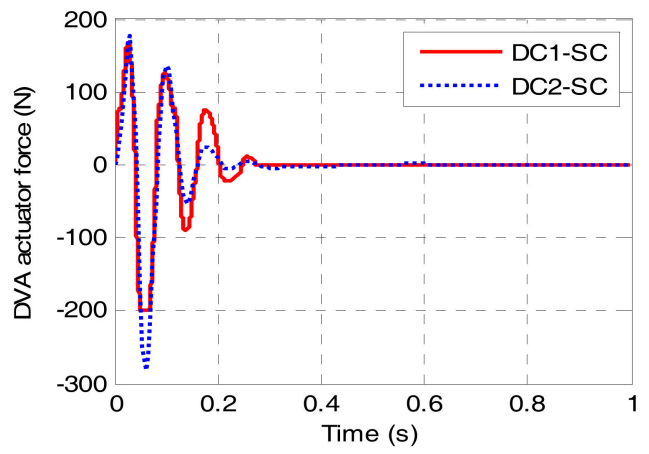

(b)

Figure 22. Actuator controlled force: (a) Suspension actuator force; (b) DVA actuator force.

\section{Conclusions}

In this paper, an integrated design scheme and an optimization control method for DVA-based electric wheels are proposed to suppress the electric wheel vibration and improve vehicle ride comfort. The IWM is considered as a DVA which is isolated from the unsprung mass by using a in-wheel spring and a damper. The configurations of the DVA-based electric wheels with either outer-rotor motor or inner-rotor motor are described. The spring stiffness and damping of the DVA are optimized for the typical conditions by using the PSO algorithm, and meanwhile a DVA actuator force is further controlled by using the alterable-domain-based fuzzy method. In addition, a suspension actuator force is optimally determined by using the LQR algorithm. Through a comparing study on the performance of the electric wheel with different structure and control schemes, it is concluded that the proposed 
DVA system exhibits excellent performance in terms of electric wheel vibration suppression and vehicle comfort improvement as well.

Note that a band-limited noise of the suspension and DVA actuators are considered in this study. Nevertheless, the realization of the controlled force differs in different types of actuators, and the environmental disturbance and system uncertainties in practical actuators are more complicated. In addition, the proposed integrated configuration is practically complicated for engineering manufacture, due to the severe constraints such as the limited wheel inner space, the coupled subsystems. These will be further investigated in our future study.

Acknowledgments: The project is supported by the National Nature Science Foundation of China (No. 51605214), the Nature Science Foundation of Jiangxi Province (No. 20171BAB216028) and the Open Research Subject of Key Laboratory of Automobile Engineering of Sichuan Province (No. sjzz2016-082).

Author Contributions: Mingchun Liu and Feihong Gu developed the integration design and the control strategy. Juhua Huang and Ming Cao investigated the simulation results. Changiiang Wang helped with simulations and the language checking. All authors carried out the data analysis and contributed to writing the paper.

Conflicts of Interest: The authors declare no conflict of interest.

\section{References}

1. Sun, F.; Xiong, R.; He, H. A systematic state-of-charge estimation framework for multi-cell battery pack in electric vehicles using bias correction technique. Appl. Energy 2016, 162, 1399-1409. [CrossRef]

2. $\mathrm{Wu}, \mathrm{X} . ; \mathrm{Hu}, \mathrm{X} . ;$ Moura, S.; Yin, X.; Pickert, V. Stochastic control of smart home energy management with plug-in electric vehicle battery energy storage and photovoltaic array. J. Power Sources 2016, 333, 203-212. [CrossRef]

3. Xiong, R.; Cao, J.; Yu, Q. Reinforcement learning-based real-time power management for hybrid energy storage system in the plug-in hybrid electric vehicle. Appl. Energy 2018, 211, 538-548. [CrossRef]

4. Xiong, R.; Tian, J.; Mu, H.; Wang, C. A systematic model-based degradation behavior recognition and health monitoring method for lithium-ion batteries. Appl. Energy 2017, 207, 372-383. [CrossRef]

5. Sachs, C.; Burandt, S.; Mandelj, S.; Mutter, R. Assessing the market of light electric vehicles as a potential application for electric in-wheel drives. In Proceedings of the 6th International Electric Drives Production Conference, Nuremberg, Germany, 30 November-1 December 2016.

6. Xiong, R.; Zhang, Y.; He, H.; Zhou, X.; Pecht, M. A double-scale, particle-filtering, energy state prediction algorithm for lithium-ion batteries. IEEE Trans. Ind. Electron. 2017. [CrossRef]

7. George, A.; Besselink, I. Rear suspension design for an in-wheel-drive electric car. J. Automob. Eng. 2016, 230, 147-159. [CrossRef]

8. Wang, R.; Hu, C.; Yan, F.; Chadli, M. Composite Nonlinear Feedback Control for Path Following of Four-Wheel Independently Actuated Autonomous Ground Vehicles. IEEE Trans. Intell. Transp. Syst. 2016, 17, 2063-2074. [CrossRef]

9. Hung, Y.; Wu, C. A combined optimal sizing and energy management approach for hybrid in-wheel motors of EVs. Appl. Energy 2015, 139, 260-271. [CrossRef]

10. Zhang, G.; Zhang, H.; Huang, X.; Wang, J.; Yu, H.; Graaf, R. Active Fault-Tolerant Control for Electric Vehicles With Independently Driven Rear In-Wheel Motors Against Certain Actuator Faults. IEEE Trans. Control Syst. Technol. 2016, 24, 1557-1572. [CrossRef]

11. Schalkwyk, D.; Kamper, M. Effect of Hub Motor Mass on Stability and Comfort of Electric Vehicles. In Proceedings of the 2006 IEEE Vehicle Power and Propulsion Conference, Windsor, UK, 1-6 September 2006.

12. Murata, S. Innovation by in-wheel-motor drive unit. Veh. Syst. Dyn. 2012, 50, 807-830. [CrossRef]

13. Wang, R.; Chen, Y.; Feng, D.; Huang, X.; Wang, J. Development and performance characterization of an electric ground vehicle with independently actuated in-wheel motors. J. Power Sources 2011, 196, 3962-3971.

14. Katsuyama, E.; Omae, A. Improvement of Ride Comfort by Unsprung Negative Skyhook Damper Control Using In-Wheel Motors. SAE Int. J. Altern. Powertrains 2016, 5, 214-221. [CrossRef]

15. Tokita, T.; Goto, H.; Ichinokura, O. An effect of Electromagnetic Force on Acoustic Noise of Axial-gap In-wheel SR Motor. In Proceedings of the 2014 International Conference on Electrical Machines (ICEM), Berlin, Germany, 2-5 September 2014. 
16. Tan, D.; Lu, C.; Zhang, X. Dual-loop PID control with PSO algorithm for the active suspension of the electric vehicle driven by in-wheel motor. J. Vibroeng. 2016, 18, 3915-3929. [CrossRef]

17. Zhang, Y.; Chen, X.; Guo, K.; Zhang, X.; Li, S. Electro-hydraulic damper for energy harvesting suspension: Modeling, prototyping and experimental validation. Appl. Energy 2017, 199, 1-12. [CrossRef]

18. Zhang, X.; Li, Z.; Guo, K.; Zheng, F.; Wang, Z. A novel pumping magnetorheological damper: Design, optimization, and evaluation. J. Intell. Mater. Syst. Struct. 2017, 28, 2339-2348.

19. Bououden, S.; Chadli, M.; Karimi, H. A Robust Predictive Control Design for Nonlinear Active Suspension Systems. Asian J. Control. 2016, 18, 122-132. [CrossRef]

20. Pepe, G.; Carcaterra, A. VFC-Variational Feedback Controller and its application to semi-active suspensions. Mech. Syst. Sig. Process. 2016, 76, 72-92. [CrossRef]

21. Zhang, B.; Han, Q.; Zhang, X.; Yu, X. Sliding Mode Control With Mixed Current and Delayed States for Offshore Steel Jacket Platforms. IEEE Trans. Control Syst. Technol. 2014, 22, 1769-1783. [CrossRef]

22. Zhang, B.; Han, Q.; Zhang, X. Recent advances in vibration control of offshore platforms. Nonlinear Dyn. 2017, 89, 755-771. [CrossRef]

23. Jin, L.; Yu, Y.; Fu, Y. Study on the ride comfort of vehicles driven by in-wheel motors. Adv. Mech. Eng. 2016, 8, 9. [CrossRef]

24. Jing, H.; Wang, R.; Li, C.; Wang, J.; Chen, N. Fault-tolerant control of active suspensions in in-wheel motor driven electric vehicles. Int. J. Veh. Des. 2015, 68, 22-36. [CrossRef]

25. Shao, X.; Naghdy, F.; Du, H. Reliable fuzzy H-infinity control for active suspension of in-wheel motor driven electric vehicles with dynamic damping. Mech. Syst. Sig. Process. 2017, 87, 365-383. [CrossRef]

26. Chen, C.; Xiong, R.; Shen, W. A Lithium-Ion Battery-in-the-Loop Approach to Test and Validate Multiscale Dual H Infinity Filters for State-of-Charge and Capacity Estimation. IEEE Trans. Power Electron. 2018, 33, 332-342. [CrossRef]

27. Xiong, R.; Yu, Q.; Wang, L.; Lin, C. A novel method to obtain the open circuit voltage for the state of charge of lithium ion batteries in electric vehicles by using H infinity filter. Appl. Energy 2017, 207, 346-353. [CrossRef]

28. Zhang, H.; Wang, J.M. Active Steering Actuator Fault Detection for an Automatically-Steered Electric Ground Vehicle. IEEE Trans. Veh. Technol. 2017, 66, 3685-3702. [CrossRef]

29. Wang, R.; Zhang, H.; Wang, J. Linear Parameter-Varying Controller Design for Four-Wheel Independently Actuated Electric Ground Vehicles With Active Steering Systems. IEEE Trans. Control Syst. Technol. 2014, 22, 1281-1296.

30. Tan, D.; Lu, C. The Influence of the Magnetic Force Generated by the In-Wheel Motor on the Vertical and Lateral Coupling Dynamics of Electric Vehicles. IEEE Trans. Veh. Technol. 2016, 65, 4655-4668. [CrossRef]

31. Mao, Y.; Zuo, S.; Wu, X.; Duan, X. High frequency vibration characteristics of electric wheel system under in-wheel motor torque ripple. J. Sound Vib. 2017, 400, 442-456.

32. Lehr, M.; Reis, K.; Binder, A. Comparison of axial flux and radial flux machines for the use in wheel hub drives. Elektrotech. Inf. 2015, 132, 25-32. [CrossRef]

33. Takahashi, T.; Takemoto, M.; Ogasawara, S.; Hino, W.; Takezaki, K. Size and Weight Reduction of an In-Wheel Axial-Gap Motor Using Ferrite Permanent Magnets for Electric Commuter Cars. IEEE Trans. Ind. Appl. 2017, 53, 3927-3935. [CrossRef]

34. Nikam, S.; Rallabandi, V.; Fernandes, B. A High-Torque-Density Permanent-Magnet Free Motor for in-Wheel Electric Vehicle Application. IEEE Trans. Ind. Appl. 2012, 48, 2287-2295. [CrossRef]

35. Luo, Y.; Tan, D. Lightweight design of an in-wheel motor using the hybrid optimization method. J. Automob. Eng. 2013, 227, 1590-1602. [CrossRef]

36. Luo, Y.; Tan, D. Study on the Dynamics of the In-Wheel Motor System. IEEE Trans. Veh. Technol. 2012, 61, 3510-3518.

37. Tan, D.; Lu, C.; Ren, C. Optimal matching between the suspension and the rubber bushing of the in-wheel motor system. J. Automob. Eng. 2015, 229, 758-769. [CrossRef]

38. Nagaya, G.; Wakao, Y.; Abe, A. Development of an in-wheel drive with advanced dynamic-damper mechanism. JSAE Rev. 2003, 24, 477-481. [CrossRef]

39. Chen, X.; Yin, J.; Wang, W.; Wu, L.; Tang, F. Approaches to diminish large unsprung mass negative effects of wheel side drive electric vehicles. J. Adv. Mech. Design Syst. Manuf. 2016, 10, 17. [CrossRef] 
40. Wang, R.; Jing, H.; Yan, F.; Karimi, H.; Chen, N. Optimization and finite-frequency H-infinity control of active suspensions in in-wheel motor driven electric ground vehicles. J. Frankl. Inst. Eng. Appl. Math. 2015, 352, 468-484. [CrossRef]

41. Ma, Y.; Deng, Z.; Xie, D. Control of the Active Suspension for In-Wheel Motor. J. Adv. Mech. Design Syst. Manuf. 2013, 7, 535-543. [CrossRef]

42. Dezasse, M.; Ahmed, M.; Brembeck, J.; Svaricek, F. Experimental Evaluation of Linear Parameter-Varying Semi-Active Suspension Control. In Proceedings of the 2016 IEEE Conference on Control Applications, Buenos Aires, Argentina, 19-22 September 2016.

43. Zhao, L.; Zhou, C.; Yu, Y. Damping Parameters Identification of Cabin Suspension System for Heavy Duty Truck Based on Curve Fitting. Shock Vib. 2016, 2016, 3051357.

44. Marinakis, Y.; Migdalas, A.; Sifaleras, A. A hybrid Particle Swarm Optimization-Variable Neighborhood Search algorithm for Constrained Shortest Path problems. Eur. J. Oper. Res. 2017, 261, 819-834. [CrossRef]

45. Liu, M.; Gu, F.; Zhang, Y. Ride Comfort Optimization of In-Wheel-Motor Electric Vehicles with In-Wheel Vibration Absorbers. Energies 2017, 10, 1647. [CrossRef]

(C) 2017 by the authors. Licensee MDPI, Basel, Switzerland. This article is an open access article distributed under the terms and conditions of the Creative Commons Attribution (CC BY) license (http:/ / creativecommons.org/licenses/by/4.0/). 